anthropology \& materialism

\section{Anthropology \& Materialism}

A Journal of Social Research

Special Issue | I | 2017

Discontinuous Infinities

\title{
Die Willkür der Zeichen
}

Zu einem sprachphilosophischen Grundmotiv Walter Benjamins

\section{Irving Wohlfarth}

\section{(2) OpenEdition}

Journals

Electronic version

URL: http://journals.openedition.org/am/815

DOI: $10.4000 / a m .815$

ISSN: 2364-0480

Publisher:

CETCOPRA, CRASSH - Center for Research in the Arts Social Sciences and Humanities, Fakultät Gestaltung - Universität der Künste Berlin

Electronic reference

Irving Wohlfarth, «Die Willkür der Zeichen », Anthropology \& Materialism [Online], Special Issue |

I | 2017, Online erschienen am: 02 März 2017, abgerufen am 22 April 2019. URL : http:// journals.openedition.org/am/815; DOI : 10.4000/am.815

This text was automatically generated on 22 avril 2019.

Tous droits réservés 


\title{
Die Willkür der Zeichen
}

$\mathrm{Zu}$ einem sprachphilosophischen Grundmotiv Walter Benjamins

Irving Wohlfarth

Dem Andenken von Pierre Missac

\section{Benjamins und die konventionalistische Sprachtheorie}

\author{
“daß von meinem sehr besonderen \\ sprachphilosophischen Standort aus es zur \\ Betrachtungsweise des dialektischen \\ Materialismus eine - wenn auch noch so gespannte \\ und problematische - Vermittlung gibt. Zur \\ Saturiertheil der bürgerlichen Wissenschaft aber \\ gar keine". \\ Benjamin an Rychner, 1931
}

1 "Es ist gleich tödlich für den Geist", schreibt Friedrich Schlegel im Athenäum, "ein System $\mathrm{zu}$ haben und keins zu haben. Er wird sich also wohl entschließen müssen, beides zu verbinden". Daß diese Sätze, die der junge Benjamin in seiner Dissertation zitiert ${ }^{1}$, auch für sein eigenes Denken gelten, ist mit jedem neuen Band der Gesammelten Schriften zunehmend deutlich geworden. "Immer radikal, niemals konsequent", ging er nach seiner eigenen Formel zeitlebens vor und war dabei alles andere als inkonsequent. Sosehr der ungebrochene "Systembegriff des XIX. Jahrhunderts", der dem "geile[n] Drang aufs große Ganze" entsprang, eine jener imperialen "Phantasmagorien" darstellte, aus denen es in seinen Augen zu "erwachen" 55 galt, sowenig fehlte es seinem antisystematischen Oeuvre an innerer Systematik.

Schlegel sucht, heißt es in Benjamins Dissertation weiter,

eine unanschauliche Intuition des Systems, und er findet sie in der Sprache. Die Terminologie ist die Sphäre, in welcher jenseits von Diskursivität und Anschaulichkeit sich sein Denken bewegt. ${ }^{6}$ 


\section{bei den Brüdern Schlegel und Novalis schließt mit der Frage,}

ob nicht jener terminologischen Tendenz [...] für alles mystische Denken eine typische Bedeutung zukomme, deren nähere Untersuchung [...] schließlich auf das a priori, das der Terminologie jedes Denkers zugrunde liegt, führen würde. ${ }^{7}$

Man erhält damit einen Wink, wo das Apriori begraben sein mag, das der terminologischen Tendenz seines eigenen Denkens zugrunde liegt. Es ist nicht nur in einer ebenfalls mystischen Terminologie, sondern vor allem in den entscheidenden Motiven einer Sprachphilosophie zu suchen, die zugleich wesentliche Impulse seiner Geschichtsphilosophie mitbestimmt. Diese globale These, die hier nicht näher ausgeführt werden kann, soll im folgenden an einem einzigen sprachphilosophischen Terminus erläutert werden, der in mehrfacher Hinsicht als der - empfindliche - Nerv seines gesamten Denkens angesehen werden kann.

Benjamins Sprachphilosophie liegt ihrerseits nicht in systematisch abgeschlossener Gestalt vor. Sie setzt sich vielmehr aus heterogenen Denkansätzen zusammen, die unvermittelt nebeneinander fortbestehen. An erster Stelle ist das sprachtheologische Modell zu nennen, das zunächst im frühen Aufsatz "Über Sprache überhaupt und über die Sprache des Menschen" (1916) entwickelt wird. Wovon die ersten Genesiskapitel berichten, ist Benjamins kühner Bibelexegese zufolge der Sündenfall des Sprachgeistes. Dieses sprachtheologisch gewendete Motiv des verlorenen Paradieses wird im Aufsatz “ Die Aufgabe des Übersetzers" (1923) um das komplementäre Thema des wiederzugewinnenden Paradieses der einen, wahren Sprache ergänzt, die im Sündenfall verlorengegangen sein soll. Sie bilden zusammen das sprachtheologische Modell, das den geschichtsphilosophischen Rahmen des Ursprungs des deutschen Trauerspiels (1926) abgibt. Im späteren Fragment "Über das mimetische Vermögen" (1933) wird der Ursprung der menschlichen Sprache nicht mehr nach dem Vorbild der biblischen Genesisgeschichte, sondern nach einem genetisch-anthropologischen Modell eigener Prägung konstruiert. Hinweise auf einen dritten, sprachsoziologischen Ansatz sind schließlich in dem etwas später verfaßten Sammelreferat "Probleme der Sprachsoziologie" (1935) enthalten.

6 Bei aller Verschiedenheit dieser Theoriestücke deuten manche Querverbindungen auf einen inneren, wenn auch losen Zusammenhang hin. Obwohl sie auf keinen gemeinsamen Nenner zu bringen sind, ${ }^{8}$ läßt sich ohne Schwierigkeit der gemeinsame Feind namhaft machen, den sie alle mit einstimmiger Vehemenz bekämpfen. Diese bête noire ist die konventionalistische Sprachtheorie, deren Grundprämisse seit der Veröffentlichung von Ferdinand de Saussures Cours de Linguistique Generale als die These vom l'arbitraire du signe bezeichnet wird. Gilt diese These, die den alten platonischen Dialog zwischen Kratylos und Hermogenes eindeutig zugunsten des letzteren entscheidet, ${ }^{9}$ für die überwiegende Mehrzahl moderner Sprachwissenschaftler als axiomatisch, so steht für Benjamin nicht weniger fest, daß sie tief in die Irre führt. Es findet bei ihm nicht einmal eine Auseinandersetzung mit dem Konventionalismus statt. Besteht Dialektik nach Hegel darin, "in die Kraft des Gegners einzutreten", so scheint letzterer in diesem Falle keine nennenswerte Kraft zu besitzen. Die Gegenposition wird vielmehr im Vorbeigehen, ohne viel Aufhebens erledigt. "Wenn nun aber die Sprache, wie es für Einsichtige auf der Hand liegt", fängt ein Satz aus der "Lehre vom Ähnlichen" an, "nicht ein verabredetes System von Zeichen ist [...]"10. Solche einschüchternden Formulierungen legen die Frage nahe, ob damit ein mächtiger Feind verleugnet oder ein lästiger Gegner ins Nichts zurückgestoßen werden soll. Handelt es sich um eine unerschütterliche Überzeugung, um eine allergische 
Reaktion oder gar um beides zugleich? Ist eine solche Erledigung konventionalistischer Willkür selber über alle Willkür erhaben?

7 Wie bestimmend diese Tabuisierung des Konventionalismus für Benjamins Selbstverständnis gewesen ist, geht aus einem im Jahre 1924 geschriebenen Brief an Hugo von Hofmannsthal hervor, in dem er folgende Grundsatzerklärung abgibt:

Es ist von hoher Bedeutung für mich, daß Sie die Überzeugung, welche in meinen literarischen Versuchen mich leitet, so deutlich herausheben und daß Sie sie, wenn ich recht verstehe, teilen. Jene Überzeugung nämlich, daß jede Wahrheit ihr Haus, ihren angestammten Palast, in der Sprache hat, daß er aus den ältesten logoi errichtet ist und daß der so gegründeten Wahrheit gegenüber die Einsichten der Einzelwissenschaften subaltern bleiben, solange sie gleichsam nomadisierend, bald hier bald da im Sprachbereiche sich behelfen, befangen in jener Anschauung vom Zeichencharakter der Sprache, der ihrer Terminologie die verantwortungslose Willkür aufprägt. Demgegenüber erfahrt die Philosophie die segensreiche Wirksamkeit einer Ordnung, kraftwelcher ihre Einsichten jeweils ganz bestimmten Worten zustreben, deren im Begriff verkrustete Oberfläche unter ihrer magnetischen Berührung sich löst und die Formen des in ihr verschlossenen sprachlichen Lebens verrät. Für den Schriftsteller aber bedeutet dieses Verhältnis das Glück, an der Sprache, welche dergestalt vor seinen Augen sich entfaltet, den Prüfstein seiner Denkkraft zu besitzen. So versuchte ich vor Jahren, die alten Worte Schicksal und Charakter aus der terminologischen Fron zu befreien und ihres ursprünglichen Lebens im deutschen Sprachgeiste aktual habhaft zu werden. ${ }^{11}$

Zwei grundverschiedene Positionen, die einen archetypischen Gegensatz bilden, werden in diesem sprachphilosophischen Credo gegenübergestellt: eine Zeichentheorie der Sprache, die dem arbeitsteiligen Wissenschaftsbetrieb zugeordnet wird, und eine offenbarungstheorie der Wahrheit, die in der Sprache selber begründet sein und ihre philologische Bestätigung ${ }^{12}$ in der schriftstellerischen Praxis finden soll. Wir werden auf die weiteren Gegensatzpaare, die sich symmetrisch um diese zwei Positionen herum gruppieren, noch zurückkommen müssen. Halten wir zunächst jedoch den prinzipiellen Antagonismus selber fest. Die eine Position, die das sprachwissenschaftliche Gegenstück zum philosophischen Nominalismus darstellt, behauptet, das Verhältnis zwischen Zeichen und Bezeichnetem sei willkürlich festgelegt. Die menschliche Sprache bilde deshalb ein verabredetes System von Zeichen, die sich einzig im Unterschied zueinander definieren. Darauf wird hier mit unverhohlenem theoretischen Affekt entgegnet, daß diese Behauptung selber bezeichnend sei, und zwar als symptomatisches Zeichen dessen, was sie bezeichnen will. Willkürlich ist Benjamin zufolge nicht so sehr die Sprache selber, als vielmehr die befangene Meinung, die sie dafür hält. Der Begriff der Willkür kehrt sich damit wie ein Bumerang gegen die sogenannte Wissenschaft, die ihn im Munde führt. Indem die Sprachwissenschaft die Sprache für willkürlich erklärt, praktiziert sie blindlings ihre eigene falsche Theorie. Beruht die Sprache nämlich nur auf äußerer Verabredung, der bei aller Immanenz der sich gegenseitig definierenden Zeichen jegliche innere Motivation abgeht, dann können solche Sprachregelungen beliebig neu getroffen werden. Insofern wirkt sich die "Anschauung vom Zeichencharakter der Sprache" zersetzend auf die Sprache selber aus. Der sprachwissenschaftliche Begriff der Willkür rechtfertigt einen willkürlichen Umgang mit der Sprache. Wo solche Beliebigkeit das Wort hat, da herrscht Benjamin zufolge die schlechte Unendlichkeit überzähliger, parasitärer Neuschöpfungen, die die Quelle trüben, aus der sie geschöpft werden. ${ }^{13}$ Man vergreift sich an einer unersetzlichen Erbschaft, indem man "bald hier bald da im Sprachbereiche" sich behilft. 
Dafür ist Benjamin zufolge die Zeichentheorie der Sprache selber ein bemerkenswertes Beispiel. Sie prägt "ihrer Terminologie die verantwortungslose Willkür" auf, indem sie den Begriff der Willkür selber zu ihrem terminologischen Kernstück erhebt. Denn die Rede von der Willkür des Zeichens ist ihrerseits eine willkürliche Sprachregelung. Sie zeichnet sich vor anderen Beispielen sprachlicher Willkür dadurch aus, daß sie sich selber gleichsam illustriert. Sie beweist nicht, was sie beweisen will: daß die Zeichen willkürlich sind. (Insofern sie's doch tut, bleibt diese Einsicht "subaltem"). Sie verrät unwillkürlich, daß Zeichen willkürlich werden können; oder aber - wie wir Benjamins frühem Sprachaufsatz noch entnehmen werden - daß sie es geworden sind. So ließe sich der zentrale Gedanke der oben zitierten Briefstelle weiterspinnen.

Gegen diese globale Verurteilung ihres Grundaxioms, die ein metaphysisches Verdammungswort mit einem philologischen Anspruch zu vereinigen scheint, wäre freilich von Seiten der Linguistik einzuwenden, daß sie auf einer unzulässigen Sinnverdrehung beruhe, die in der Tat mehr mit dem Glück des freien Schriftstellers als mit strenger Wissenschaft zu tun habe. In der Konfrontation, die wir hier unterstellen, wird der jeweilige Vorwurf der Willkür abwechselnd von beiden Seiten erhoben und zurückgewiesen. Nicht ihr Begriff der Willkür sei willkürlich, antwortet die Sprachwissenschaft, sondern Benjamins eigenwilliger Umgang mit ihm. Der eindeutig festgelegte Sinn eines terminus technicus werde mit der Vieldeutigkeit seines alltäglichen oder literarischen Gebrauchs verwechselt. Darauf ist wiederum eine implizite Antwort aus Benjamins Brief herauszulesen. Um sie zu erhalten, braucht man lediglich den Hinweis auf die "alten Worte Schicksal und Charakter" auf den Begriff der Willkür auszudehnen. Weit entfernt, den Vorwurf der Willkür zu rechtfertigen, wäre die inkriminierte Sinnverschiebung dazu bestimmt, ein Wort - die Willkür selbst - vor seiner willkürlichen Entstellung zu retten. ${ }^{14}$ Auch in diesem Fall soll ein Wort von seiner "terminologischen Fron" befreit werden. Das soll durch eine Art freier Assoziation geschehen, die mit schlafwandlerischer Sicherheit jenseits aller subjektiven Willkür zur Objektivität der Sprache selbst zurückfindet. Ein ursprüngliches, semantisch geladenes Wort steht gegen die worttaube Terminologie auf, die das "in ihr verschlossene sprachliche Leben" weiterhin unterdrückt.

11 Solche keimfreie Terminologie dichtet Benjamin zufolge die Sprache gegen die Geschichte ab, die in ihr lebt. "Eine Wissenschaft, die sich im Protest gegen die Sprache ihrer Untersuchung ergeht", heißt es in der Erkenntniskritischen Vorrede zum Trauerspielbuch,

ist ein Unding. Worte sind, neben den Zeichen der Mathematik, das einzige Darstellungsmittel der Wissenschaft und sie selber sind keine Zeichen. Denn im Begriff, als welchem freilich das Zeichen entspräche, depotenziert sich eben dasselbe Wort, das als Idee sein Wesenhaftes besitzt.

12 Das gilt a fortiori für die Wissenschaft, welche Sprache überhaupt als ein System willkürlicher Zeichen, und damit zugleich das Mikrosystem ihrer eigenen Terminologie d.h. Worte wie Zeichen und Willkür - grundsätzlich mißversteht. ${ }^{15}$ Metaphysischphilologisches Eingedenken tut not, um die "im Begriff verkrustete Oberfläche" der Sprache wieder aufzubrechen. Erst durch solche Anamnesis wäre die Idee der Willkür vom Begriff der Willkür - von der Willkür des Begriffs - erlöst. Der Begriff steht nämlich im selben verfallsgeschichtlichen Verhältnis zur Idee wie das Zeichen zum Wort.

13 Zwei unversöhnliche Auffassungen der Sprache werden hier miteinander konfrontiert. Sprache wird jeweils als Verabredung aufgefaßt. Ein "verabredetes System von Zeichen" 
wird einem Bild der Sprache gegenübergestellt, das Benjamins Vorstellung von Geschichte als einer "geheimen Verabredung" entspricht, die "zwischen den gewesenen Geschlechtern und unserem"16 bestehe. Anstatt Zeichen wie Münzen ständig neu prägen zu müssen, empfangen wir die entscheidenden Signale von der Sprache selber: vom Kanon der sprachlichen Überlieferung. Das Verständnis von Sprache und Geschichte bedeutet nicht nur, daß wir sie, sondern daß sie sich durch uns hindurch verstehen. "In dem Aufsatz 'Über die Unverständlichkeit'", notiert Benjamin in seiner Dissertation,

will Schlegel zeigen, 'daß die Worte sich selbst oft besser verstehen, als diejenigen, von denen sie gebraucht werden, [...] daß es unter den philosophischen Worten [...] geheime Ordensverbindungen geben muß; [...] daß man die reinste und gediegenste Unverständlichkeit gerade aus der Wissenschaft und aus der Kunst erhält, die ganz eigentlich aufs Verständigen und Verständlichmachen ausgehen, aus der Philosophie und Philologie. ${ }^{17}$

14 Demgegenüber tut die Willkür eigenmächtiger Sprachregelungen der Sprache eine Gewalt an, die sie ihrer ursprünglichen Gewalt, ihrer geheimen Kräfte beraubt. ${ }^{18}$ Solche Willkür ist ein ohnmächtiges Diktat, und ihre Zeichen depotenzierte Worte. Sie ist deshalb "verantwortungslos", weil sie keine entsprechende Antwort auf die alten Worte zu geben versteht.

Antworten kann jedoch nur, wer zuhört. Sprachvergessenheit, nicht Seinsvergessenheit, gilt hier als die Erbsünde. Auf das Weltbild des bürgerlichen Subjekts, das sich nach der Marxschen Formel eine Welt nach seinem Ebenbilde schafft, wird bei Benjamin mit einer Theorie der Aura geantwortet. Auch Worte werden mit dem Vermögen belehnt, “den Blick aufzuschlagen"19. Nicht - wie bei Baudelaire - die Natur, sondern die Sprache stellt die Welt symbolischer Entsprechungen dar. ${ }^{20}$ Als ein Kraftfeld magnetischer correspondances entspricht sie zugleich Benjamins Vorstellung von Geschichte. So wie philosophische "Einsichten jeweils ganz bestimmten Worten zustreben", "so strebt, kraft eines Heliotropismus geheimer Art, das Gewesene der Sonne sich zuzuwenden, die am Himmel der Geschichte im Aufgehen ist"21, wobei unsere "eigene Epoche mit einer ganz bestimmten früheren"22 in eine einmalige Konstellation tritt. Sprache und Geschichte besitzen beide dieselbe "segensreiche Wirksamkeit einer Ordnung", innerhalb derer geheime Ordensverbindungen und Verabredungen stattfinden. Gute Schriftsteller und Geschichtsschreiber sind die Medien solcher Ereignisse. Ihre Feder ist gleichsam die "divinatorische"23 Wünschelrute, die es zu den sprachgeschichtlichen Quellen zieht. Das glückliche Verhältnis, das sich günstigenfalls zwischen Wort und Sache, Einsicht und Sprache, Jetzt und Einst einstellt, wird also nicht willkürlich festgesetzt, sondern fällt uns, wie die tiefsten, glücklichsten Erinnerungen, unwillkürlich zu. Zufällig sind solche Einfälle, ohne darum willkürlich zu sein. Der objektive Zufall solcher Begegnungen ist so überdeterminiert wie die freie Assoziation. Die geheimen Zeichen, die dabei ausgetauscht werden, deuten auf eine "magnetische" Wahlverwandtschaft zwischen zwei (vor)bestimmten Partnern hin, die einander im Dunkeln suchen. Bestimmung ("zu finden bestimmt"24), Bestimmtheit und Stimme ("ist nicht in Stimmen, denen wir unser Ohr schenken, ein Echo von nun verstummten?"25) bilden dabei einen einzigen Zusammenhang, der ihre wortgeschichtliche Aura ausmacht. Nur dort ist das "ganz bestimmte" Wort zu entdecken, dem eine Einsicht zustrebt, wo es nicht so sehr vom Subjekt her bestimmt wird, als sich von selbst zu Worte meldet. "Die Wahrheit ist der Tod der Intention"26.

16 Klingt die gedrängte Erklärung, die Benjamin 1924 an Hofmannsthal abgibt, an gewisse Motive aus der deutschen Frühromantik an, so nimmt sie zugleich die Metaphorik der 
Fundamentalontologie vorweg. ${ }^{27}$ Ist bei Heidegger vom "Haus des Seins" die Rede, so hat bei Benjamin jede Wahrheit "ihr Haus, ihren angestammten Palast" in der Sprache. Die majestätischen Pfeiler dieses versunkenen Schlosses sind "aus den ältesten logoi errichtet" worden: Baudelaires correspondances verweisen auf "das frühere Leben" ${ }^{28}$. Eine Serie mehr oder weniger expliziter Gegensatzpaare reiht sich an Benjamins Gegenüberstellung einer ursprünglichen mit einer sprachvergessenen Auffassung der Sprache an: Ursprache, monotheistische Wahrheit, Grund und Boden, hoher Adel, Alteingesessenheit und sichere Fundamente auf der einen Seite, beliebige Zeichen, schlechte Unendlichkeit, geistiges Nomadentum, subalterne Wissenschaft, improvisatorische Notbehelfe, Usurpation auf der anderen. So eklektisch die einzelnen Momente dieses gebündelten Gegensatzes anmuten mögen, Eklektizismus gehört innerhalb dieser Gegenüberstellung der schlechten Seite an. Das dichte ideologische Geflecht, das hier zum Vorschein kommt, deutet vielmehr darauf hin, daß die Gegenüberstellung ihrerseits einer grösseren geschichtlichen Konstellation angehört. Es ist wohl kaum ein Zufall, wenn Scholem zur gleichen Zeit damit beschäftigt ist, die Geheimtradition der jüdischen Theologie - die Kabbala - auszugraben, die eine bürgerlich assimilierte "Wissenschaft von Judentum" verschüttet hatte. Gegen "Einzelwissenschaften" und "Wissenschaftsbetrieb" setzt der Autor des Trauerspielbuchs zwei Jahre später eine "Wissenschaft vom Ursprung" ein, deren esoterische Seite weder verleugnet noch gerühmt werden soll. ${ }^{29}$ Dieser Wissenschaft vom Ursprung liegt eine jüdische Sprachtheologie zugrunde. (Letztere hat in diesem Zusammenhang ein vergleichbares Verhältnis zum akademischen Wissenschaftsbetrieb wie der Feudaladel zum aufstrebenden Bürgertum, und wird dann später einen angemessenen Bündnispartner im historischen Materialismus finden: so wenig sich jüdische Substanz durch das Bürgertum assimilieren lassen soll, so sehr soll sie sich dann dem historischen Materialismus einverleiben). Das Fundament der Wahrheit soll die - eine, feste, edle Sprache sein. Während die seßhafte Wahrheit in ihrem angestammten Palast thront, irren die subalternen Wissenschaften, die das königliche Haus entweder verlassen oder nie gekannt haben, in der Wüste ziellos umher. Solche Metaphorik stellt eine grandiose Rollenvertauschung vor. Die etablierte Wissenschaft wird von einem jüdischen Außenseiter im Namen jener bodenständigen Werte verurteilt, die sonst zum Arsenal des Antisemitismus gehören. ${ }^{30}$

Wo die Wissenschaft nicht mehr in der Sprache gegründet ist, verliert sie Benjamin zufolge den Boden unter den Füßen. "Die Anschauung vom Zeichencharakter der Sprache" ist folglich kein beliebiger Irrtum, sondern die irrige Rechtfertigung einer irrenden Beliebigkeit, die auf ein ursprüngliches Irrewerden zurückgeht. Dieser Grundirrtum soll darin bestanden haben, den Grund der Sprache zu verlassen. Die Wüste, die in jenem Augenblick entsteht, der Abgrund, der sich damit auftut, ist die Beliebigkeit. Auf den brüchigen Fundamenten dieses Abgrunds, den sie verschüttet, wird dann im Laufe der Zeit die Zeichentheorie der Sprache aufgebaut. Sie besiegelt die Beliebigkeit mit einem wissenschaftlichen Alibi. Wie diese unwissende Wissenschaft sich vor dem Richtstuhl der Benjaminschen Sprachtheologie selber richtet, soll jetzt erläutert werden. 


\title{
II. Die Geburt der Willkür der Zeichen aus dem Sündenfall des Sprachgeistes
}

\author{
"Une Idee, une Forme, un Etre \\ Parti de l'azur et tombe \\ Dans un Styx bourbeux et plombé \\ Où nul oeil du Ciel ne pénètre"
}

Gleich am Anfang des frühen Aufsatzes "Über Sprache überhaupt und über die Sprache des Menschen" wird eine "Alternative" aufgestellt, "vor der mit Sicherheit die wesentlich falsche Meinung von der Sprache" sich verraten soll.

Teilt der Mensch sein geistiges Wesen durch die Namen mit, die er den Dingen gibt? Oder in ihnen? In der Paradoxie dieser Fragestellung liegt ihre Beantwortung. Wer da glaubt, der Mensch teile sein geistiges Wesen durch die Namen mit, der kann wiederum nicht annehmen, daß es sein geistiges Wesen sei, das er mitteile, - denn das geschieht nicht durch Namen von Dingen, also durch Worte, durch die er ein Ding bezeichnet. Und er kann wiederum nur annehmen, er teile eine Sache anderen Menschen mit, denn das geschieht durch das Wort, durch das ich ein Ding bezeichne. Diese Ansicht ist die bürgerliche Auffassung der Sprache, deren Unhaltbarkeit und Leere sich mit steigender Deutlichkeit im folgenden ergeben soll. Sie besagt: Das Mittel der Mitteilung ist das Wort, ihr Gegenstand die Sache, ihr Adressat ein Mensch. Dagegen kennt die andere kein Mittel, keinen Gegenstand, und keinen Adressaten der Mitteilung. Sie besagt: im Namen teilt das geistige Wesen des Menschen sich Gott mit. ${ }^{31}$

Als "Sprachgemeinschaft" mit Gottes Wort ist diese Namenssprache zugleich mit der Sprache der Dinge verbunden:

Das menschliche Wort ist der Name der Dinge. Damit kann die Vorstellung nicht mehr aufkommen, die der bürgerlichen Ansicht der Sprache entspricht, daß das Wort zur Sache sich zufällig verhalte, daß es ein durch irgendwelche Konvention gesetztes Zeichen der Dinge (oder ihrer Erkenntnis) sei. Die Sprache gibt niemals bloße Zeichen. ${ }^{32}$

Die Wahl zwischen der bürgerlichen und der theologischen Auffassung der Sprache soll also ihrerseits alles andere als beliebig sein. An die Stelle der synchronen Alternative, die hier gestellt wird, tritt im weiteren Verlauf des Aufsatzes eine verfallsgeschichtliche Genealogie. Während die richtige Theorie eine kreisförmige Sprachbewegung nachzeichnet, deren Alpha und Omega ("Ursprung ist das Ziel"33) Gott selber ist, stellt sich die falsche Meinung implizit als eine letzte Konsequenz des Sündenfalls heraus.

Der Sündenfall des Sprachgeistes bestand in der Zersetzung der paradiesischen Ursprache, die jedes Ding bei seinem eigenen Namen nannte. Das vorbürgerliche Verhältnis Adams zu den Dingen war ein quasi feudales. Aber noblesse oblige. Indem Adam den Dingen den "Adel" ihres Namens verleiht, empfängt er zugleich ihre eigene Sprache. Benjamins Theorie der Aura wäre auch in dieser Hinsicht in seiner Sprachtheologie angelegt. Aura wäre die Ausstrahlung des göttlichen Logos, die der Schöpfung und dem Namen gemeinsam ist.

Im Namen ist das Wort Gottes nicht schaffend geblieben, es ist an einem Teil empfangend, wenn auch sprachempfangend, geworden. Auf die Sprache der Dinge selbst, aus denen wiederum, lautlos und in der stummen Magie der Natur das Wort Gottes hervorstrahlt, ist diese Empfängnis gerichtet. ${ }^{34}$ 
Die adamitische Namensgebung ist die Übersetzung einer stum
Sprache. Sie nimmt am großen Kreislauf des göttlichen Logos teil.

Alle höhere Sprache ist Übersetzung der niederen, bis in der letzten Klarheit sich das Wort Gottes entfaltet, das die Einheit dieser Sprachbewegung ist. ${ }^{35}$

23

Aber das menschliche Wort nimmt innerhalb dieser logozentrischen Bewegung eine einzigartige Stelle ein. Gott wollte den Menschen

nicht der Sprache unterstellen, sondern im Menschen entließ Gott die Sprache, die ihm als Medium der Schöpfung gedient hatte, frei aus sich. Gott ruhte, als er im Menschen sein Schöpferisches sich selbst überliess. ${ }^{36}$

Dieser sprachliche Spielraum soll jedoch nichts Spielerisches an sich haben:

Das adamitische Namengeben ist so weit entfernt Spiel und Willkür zu sein, daß vielmehr gerade in ihm der paradiesische Stand sich als solcher bestätigt, der mit der mitteilenden Bedeutung der Worte noch nicht zu ringen hatte. ${ }^{37}$

Die Freiheit des ersten Menschen ist so lange vor der Versuchung der Willkür gefeit, als sie in der Sprache der Dinge gegründet ist. Seine Worte hören auf, die eine, wahre, ernste, motivierte, naiv-realistische, entsprechende Namenssprache zu sein, wo sie kein Fundament in der Sache mehr haben. Anstatt unmittelbar, in intentio recta bei den Dingen $\mathrm{zu}$ verweilen, schielt der gefallene Mensch nach Intersubjektivität. ${ }^{38}$ Zwischenmenschliche Kommunikation wäre in diesem Zusammenhang von instrumenteller Mittelbarkeit und subjektiver Herrschaft, von gegenseitiger Konkurrenz und endloser Diskussion: von mangelnder Gemeinsamkeit nicht zu trennen.

Mit dieser "Abkehr von jenem Anschauen der Dinge, in dem deren Sprache dem Menschen eingeht" ${ }^{39}$, vollzieht sich der Sündenfall des Sprachgeistes. Das auratische Einvernehmen zwischen Mensch und Schöpfung wird grundlos gekündigt, Freiheit wird durch Willkür, Name durch Zeichen (z)ersetzt, der "Abgrund des Geschwätzes" 40 tut sich auf. L'arbitraire du signe ist m.a.W. eine Formel, die in diesem Zusammenhang den Sündenfall bezeichnet. Denn der "Verfall des seligen Sprachgeistes" ${ }^{41}$ fällt sowohl mit dem "Triumph der Subjektivität und dem Anbruch einer Willkürherrschaft über Dinge" ${ }^{42}$, als auch mit der "Geburtsstunde" 43 des Zeichens zusammen. In diesem Augenblick tritt die Sprache aus der "immanenten eigenen Magie" heraus, um "ausdrücklich, von außen gleichsam, magisch zu werden" ${ }^{\prime 4}$. Sie vertreibt sich selber aus dem Paradies und stürzt ins bodenlose, uferlose Draußen, das sie damit erfindet. Das lange Irren in der Wüste ist zugleich die große Verwirrung.

Zeichen müssen sich verwirren, wo sich die Dinge verwickeln. Zur Verknechtung der Sprache im Geschwätz tritt die Verknechtung der Dinge in der Narretei fast als deren unausbleibliche Folge. In dieser Abkehr von den Dingen, die die Verknechtung war, entstand der Plan des Turmbaus und die Sprachverwirrung mit ihm. ${ }^{45}$

Während die richtigen Worte, die Namen, les mots justes, den Dingen Gerechtigkeit widerfahren lassen, üben gefallene Worte Gewalt über sie aus. Letztere stellen eine ohnmächtige, aber verhängnisvolle "Überbenennung"46 dar. Ist der "angestammte Palast" der Sprache aus den "ältesten Logoi" errichtet, so ist der Turm zu Babel aus lauter irren Zeichen aufgebaut. Damit ergibt sich eine weitreichende Begriffskette: Willkür, Zeichen, Verknechtung, Herrschaft, Subjektivität, Äußerlichkeit, Mittelbarkeit, Abstraktion, Urteil, Sprachverwirrung, Geschwätz, Narretei, Schuld, Bedeutung usw. Das sprachphilosophische Paradigma, das mit Benjamins Deutung des Sündenfalls entsteht, 
wird sein gesamtes Denken - und darüber hinaus Adornos Beitrag zur "kritischen Theorie" ${ }^{47}$ - wesentlich mitbestimmen.

Ist die Willkür der Zeichen die Signatur des Sündenfalls, was ist dann von der Zeichentheorie der Sprache zu halten? Sie ist wohl als ein weiteres Symptom des Sündenfalls und zugleich als das namenlose "Wissen" zu deuten, das ihn verdrängt. Ihre Rede von der Willkür der Zeichen wäre vielleicht weniger eine willkürliche Konstruktion als eine unwillkürlich entstellte Wahrheit. Jedenfalls weist diese Formel bei Benjamin einerseits auf das katastrophale Ereignis, welches die Geschichte überhaupt in Bewegung setzt, und andererseits auf die Wissenschaft hin, die diese "Urgeschichte des Bedeutens" 48 48 vergessen zu haben scheint.

Die geschichtsphilosophische Konsequenz, die sich aus diesem sprachphilosophischen Paradigma ergibt, ist, daß die menschliche Geschichte sofort mit der gottverlassenen Moderne einsetzt. Ist Gott tot, dann ist alles erlaubt; wo alles erlaubt ist, dort herrscht Willkür; und wenn die gottgewollte, hierarchisch gegliederte Schöpfung einen "feudalen" Eindruck macht, dann sieht die darauffolgende Willkürherrschaft entsprechend "bürgerlich" aus. Was sonst in Geschichtsbüchern als Aufstieg einer fortschrittlichen Bürgerklasse geschildert wird, die sich von feudaler Willkür emanzipiert, wird hier umgekehrt als Absturz in die Willkürherrschaft ausgelegt. ${ }^{49}$ Und wo andere im Zeichen eine entmythologisierte Sprache sehen, erblickt Benjamin eine neue, profane Dämonie. ${ }^{50}$ Die unheimliche Zeichensprache, die die gute, "immanente" Magie der Namen zugunsten einer schlechten, "ausdrücklichen" verdrängt, breitet sich so ungehemmt wie die bürgerliche Gesellschaft aus. Der stille Kreis einer begrenzten Namenssprache wird durch die wuchernde Überproduktion beliebiger Spielmarken ersetzt. Das Zeichen ist - wie bei Marx die Ware - die Urzelle eines Systems, das - wie einst Gott - die Welt nach seinem Ebenbilde schafft.

"Die Sprache", schreibt Benjamin, "gibt niemals bloße Zeichen" - auch wenn der gefallene Mensch die Sprache "an einem Teile jedenfalls zum bloßen Zeichen" ${ }^{51}$ macht. Die ursprüngliche Namenssprache ist auch nach dem Sündenfall nicht spurlos verschwunden. Ihr im Dickicht der Zeichenwelt die Treue zu halten, ist die jeweilige "Aufgabe" des Schriftstellers, des Übersetzers und des Forschers. Diese Verantwortung wird von der bürgerlichen Zeichentheorie vollends verraten. Indem sie die Sprache auf bloße Zeichen reduziert, denkt sie die letzten Spuren ihres paradiesischen Ursprungs weg. Die bürgerliche Zeichensprache ist schon schlimm genug, aber die bürgerliche Theorie der Zeichensprache macht die Situation dadurch schlimmer, daß sie die ursprüngliche Abkehr von der Namenssprache auf wissenschaftlicher Ebene wiederholt. Besteht die Katastrophe darin, daß "es 'so weiter' geht" ${ }^{2}$, dann leistet die Zeichentheorie einen wissenschaftlichen Beitrag zu ihrer Normalisierung. Sie hilft der Katastrophe nach, indem sie die schlechte Unendlichkeit der Zeichen um ein falsches Alibi vermehrt. Sie tut, als wäre nichts geschehen, und hypostastiert den Sündenfall, von dem sie nichts wissen will, indem sie ihn mit dem Normalfall verwechselt. Darin liegt der geheime Naturalismus der konventionalistischen Sprachtheorie. Die Konvention gerinnt zur zweiten Natur. Eine wertneutrale Wissenschaft nimmt die gefallene Sprache, wie sie sie vorzufinden meint, und heißt sie gut. Dafür ist ihr Begriff der Willkür selber ein entsprechendes Indiz. Er bezeichnet den Skandal ohne ihn beim Namen zu nennen, und verrät dabei mehr, als er weiß.

31 Die nachträgliche Legitimation des Sündenfalls, welche die bürgerliche Zeichentheorie unwillkürlich liefert, stellt sich somit aus sprachtheologischer Sicht als ein Vergessen des 
Vergessens dar. ${ }^{53}$ Sie ist - wie bei Marx die politische ökonomie - eine Verdinglichung der Verdinglichung, die Verzerrung - wie beim späten Lukacs die moderne Kunst - einer verzerrten Welt. Die Katastrophe vollendet sich, indem sie ihre Spuren verwischt. Gleichwohl verrät sich die Verdrängung der Verdrängung als ein weiteres Symptom. Sie erinnert daran, daß man sich nicht mehr daran erinnert, daß man die wahre Sprache vergessen hat.

Eingangs wurde die Frage aufgeworfen, ob die bürgerliche Zeichentheorie, die Benjamin gleichsam im Vorbeigehen schneidet, einen mächtigen oder einen nichtigen Gegner darstellt. Die immanente, sprachtheologische Antwort müßte lauten: beides zugleich. Die Zeichentheorie, deren "Unhaltbarkeit und Leere" erwiesen werden soll, ist so grundlos wie der Abgrund, auf dem sie fußt. Dieser "Abgrund des Geschwätzes" bedeutet gleichzeitig ein irreales Nichts und eine tödliche Gefahr. Denn er droht - wie bei Baudelaire die Langeweile - "die Welt in einem Gähnen zu verschlucken" ${ }^{4}$. Kein Wunder also, wenn Benjamin das Geschwätz regelmäßig verdonnert. Er macht mit ihm kurzen Prozeß. Sein vernichtendes Urteil über die "falsche Meinung von der Sprache" klingt in der Tat an das göttliche "Gericht" an, vor dem "der geschwätzige Mensch, der Sündige" 55 einst gestellt wurde, um dann durch die Wucht des richtenden Wortes aus dem Paradies vertrieben zu werden..$^{56}$

\title{
III. Sprachgeschichte als Verfallsgeschichte
}

\author{
"Un Ange, imprudent voyageur \\ Qu'a tenté l'amour du difforme, \\ Au fond d'un cauchemar énorme \\ Se debattant comme un nageur" \\ Baudelaire, L'trrémédiable \\ "In diesem windigen Europa"57 \\ Dostojewski
}

Benjamin schreibt 1935, sei's konstatierend, sei's beschwörend, vom

Prozeß einer vollkommenen Umwälzung, den eine aus der weit zurückliegenden Zeit meines unmittelbar metaphysischen, ja theologischen Denkens stammende Gedanken- und Bildermasse durchmachen mußte, um mit ihrer ganzen Kraft meine gegenwärtige Verfassung zu nähren. ${ }^{58}$

Durch diesen "Umschmelzungsprozess" 59 hindurch wird sein Denken dennoch - oder deswegen - von seiner frühen Sprachphilosophie weiterhin geprägt. So läßt sich beispielsweise die abschließende Deutung, die Benjamin in den “ Geschichtsphilosophischen Thesen" vom "neuen Engel” gibt, der mehrfach bei ihm vorkommt, ${ }^{60}$ als die endgültige Wiederaufnahme jenes sprachphilosophischen Motivs begreifen, dem wir bisher in seinen theologischen Jugendschriften nachgegangen sind.

Mein Flügel ist zum Schwung bereit

ich kehrte gern zurück

denn blieb' ich auch lebendige Zeit

ich hätte wenig Glück

Gerhard Scholem, Gruß vom Angelus

Es gibt ein Bild von Klee, das Angelus Novus heißt. Ein Engel ist darauf dargestellt, der aussieht, als wäre er im Begriff, sich von etwas zu entfernen, worauf er starrt. Seine Augen sind aufgerissen, sein Mund steht offen und seine Flügel sind ausgespannt. Der Engel der Geschichte muß so aussehen. Er hat das Antlitz der Vergangenheit zugewendet. Wo eine Kette von Begebenheiten vor uns erscheint, da 
sieht er eine einzige Katastrophe, die unablässig Trümmer auf Trümmer häuft und sie ihm vor die Füße schleudert. Er möchte wohl verweilen, die Toten wecken und das Zerschlagene zusammenfügen. Aber ein Sturm weht vom Paradiese her, der sich in seinen Flügeln verfangen hat und so stark ist, daß der Engel sie nicht mehr schließen kann. Dieser Sturm treibt ihn unaufhaltsam in die Zukunft, der er den Rücken kehrt, während der Trümmerhaufen vor ihm zum Himmel wächst. Das, was wir den Fortschritt nennen, ist dieser Sturm. ${ }^{61}$ Vergangenheit festzustellen, wie es sich im Augenblick der Gefahr dem historischen Subjekt einstellt"62. Der angelus novus, der auf die gesamte bisherige Menschheitsgeschichte starrt, ist sein hilfloser Schutzpatron. Könnte sich der Engel umdrehen, so sähe die Endlösung, auf die die Weltgeschichte - Nietzsche würde sagen: der europäische Nihilismus - hintreibt. Aber die endgültige Besiegelung des Unheils könnte ihn kaum noch überraschen. ${ }^{63}$ Denn die Vergangenheit, die der Engel der Geschichte vor sich sieht, enthält schon die Zukunft. ${ }^{64}$ Auschwitz dehnt sich gleichsam vor und hinter ihm aus. Als ein "rückwärts gewandter Prophet" kehrt er

der eignen Zeit den Rücken; sein Seherblick entzündet sich an den ins Vergangene verdämmenden Gipfeln der frühem Ereignisse. Dieser Seherblick ist es, welchem die eigene Zeit deutlicher gegenwärtig ist als den Zeitgenossen, die mit ihr Schritt 'halten'.65 herweht" "0 und das Vergessen hat sich mittlerweile als jene "Abkehr" von d Dingsprache herausgestellt, die den Sündenfall verschuldet. Wo die paradiesische Namenssprache "selig in sich selbst ruht" 11 , dort herrscht die Ruhe vor dem Sturm. Darauf folgt der Lapsus linguae, wodurch die ersten Menschen sich ihre - stürmische Vertreibung aus dem Paradiese zuziehen. Indem sie aus der seligen Namenssprache heraustreten, lassen sie das Paradies fast schon hinter sich. Mit diesem Akt der Willkür fängt die Geschichte an. Der sogenannte Fortschritt, der sich immer weiter vom Paradies entfernt, erweist sich als die konsequente, lineare Fortsetzung einer Abkehr, die dem Paradies den Rücken dreht. Am Ende der Geschichte wird der Engel umgekehrt dem Fortschritt den Rücken kehren, um sich der Vergangenheit - und darüber hinaus dem 
Paradies - zuwenden zu können. Damit stellt er eine melancholische Form von Aura wieder her. Heißt nämlich die Aura einer Erscheinung erfahren, sie "mit dem Vermögen belehnen, den Blick aufzuschlagen", dann geht der "Verfall der Aura"72 mit dem "Verfall des seligen Sprachgeistes" einher. Die Sprache entspricht nicht mehr den Dingen, der Augen-Blick findet nicht mehr statt, die Verabredung wird verfehlt. Ist Aufmerksamkeit Malebranche zufolge "das natürliche Gebet der Seele" ${ }^{73}$, so hat der Mensch im Sündenfall zu beten aufgehört. Die nomadisierende Diaspora der Sprache und, ineins mit dieser Sprachverwirrung, die trostlose Verworrenheit der Weltgeschichte gehen auf diese ursprüngliche Zerstreuung zurück.

Ist "Ursprung" das "Ziel", dann führt die Versuchung, die "wir den Fortschritt nennen", im Sturmschritt des Vergessens ${ }^{74}$ vom Ziele ab. Dieser unentwegte Fortschritt ist in Wahrheit der fortschreitende Sündenfall. Er weist nicht wirklich vorwärts, sondern versinkt immer tiefer in den Abgrund. Daß er die "allegorische Physiognomie der NaturGeschichte"75 hat, besagt, daß die bisherige Menschheitsgeschichte keinen Fortschritt über die Naturgeschichte darstellt. "An Fortschritt glauben”, bemerkt Kafka, "heißt nicht glauben, daß ein Fortschritt schon geschehen ist. Das wäre kein Glauben"76. Nur eine tief gefallene Menschheit kann ihre Zurückgebliebenheit mit Fortschritt verwechseln. Nicht einmal den Abfall von der Namenssprache kann sie beim Namen nennen. Der Begriff des Fortschritts ist - wie die terminologische Rede von der Willkür des Zeichens - zu einem windigen Euphemismus geworden, der selber am Sündenfall des Sprachgeistes teilhat.

41 Ist der sogenannte Fortschritt "dieser Sturm"77, so geht er auf ein ursprüngliches Erdbeben zurück. Im Sündenfall wurde die "gemeinsame Grundlage" des Sprachgeistes mit einem Mal erschüttert. ${ }^{78}$ Auf solchen unsicheren Fundamenten wurde der Turm zu Babel dann errichtet, dessen monumentale Eitelkeit am Anfang der Geschichte wie ein Menetekel das bittere Ende schon ahnen ließ. ${ }^{79}$ Kein Wunder, wenn der Engel der Geschichte am Ende auf einen einzigen Trümmerhaufen starrt. Der "Zeit-Raum" "Natur-Geschichte"81, der sich vor seinen Augen ausdehnt, ist der ausgedehnte Sündenfall. War der angestammte Palast der Wahrheit aus den ältesten logoi errichtet worden, so stellt der Trümmerhaufen der Geschichte in einem doppelten Sinn den Abfall der Geschichte dar. Der Turm zu Babel, dessen Geschwätz schon wie der Lärm der Börse klingt, und der Trümmerhaufen der Geschichte, der an die kabbalistische Symbolik der zerbrochenen Gefäße zurückerinnert, markieren den Anfang und das Ende einer Willkürherrschaft, die auf den brüchigen Fundamenten des Zeichens steht und fällt. Der Sündenfall war schon der Anfang vom Ende, das seitdem endlos weitergeht. Wie auf einem Autofriedhof werden "unablässig Trümmer auf Trümmer" gehäuft, die als Kehricht des Fortschritts sein wahres, namenloses Gesicht darstellen. Der Trümmerhaufen schreit wie ein stummer Leichenberg zum Himmel, den er zugleich verdeckt. ${ }^{82}$ Ist diese apokalyptische Müllhalde, die wie der Turm zu Babel "zum Himmel wächst”, eine letzte Allegorie des Sündenfalls, dann setzt sie sich - so "organisch" wie bei Marx das Kapital aus einer "primitiven Akkumulation" wuchernder, totgeborener Zeichen zusammen. Das Zeichen ist das Todeszeichen, das Bruchstück, die Allegorie seiner eigenen Fehlgeburt. Die selige Namenssprache war hingegen die Mitteilung eines noch ungebrochenen symbolischen Zusammenhangs. Indem Gott dem Menschen unmittelbar von zu Mund den "Odem" einblies, gab er ihm "zugleich Leben und Geist und Sprache". Letztere war die Sprache des geistigen "Lauts", der eine symbolische Gemeinschaft mit der Natur herstellte. ${ }^{83} \mathrm{Im}$ Gegensatz zu dieser paradiesischen Namenssprache, deren "prägende Gewalt" ${ }^{84}$ sie eingebüßt haben, "prägen" die gefallenen Zeichen ihre Willkür der 
Geschichte "auf". Die lebendige Stimme wird durch eine tödliche Inschrift zum Schweigen gebracht.

Wenn mit dem Trauerspiel die Geschichte in den Schauplatz wandert, so tut sie es als Schrift. Auf dem Antlitz der Natur steht "Geschichte" in der Zeichenschrift der Vergängnis. ${ }^{85}$

Was dem Engel der Geschichte die Sprache verschlägt, ist - sprachtheologisch betrachtet - der todtraurige Anblick der zerschlagenen, sprachlos gewordenen Sprache. ${ }^{86}$ "Wo eine Kette von Begebenheiten vor uns erscheint, da sieht er eine einzige Katastrophe [...]". Und wo ein geregeltes System verabredeter Zeichen vor dem Semiologen erscheint, da sieht er einen Trümmerhaufen. Das Unheil, das die bürgerliche Wissenschaft nicht begreifen kann, wird durch sie stillschweigend beschönigt. Darin tut der Konventionalismus es dem Historismus gleich, den sie mit der "Diachronie" ausklammem will. "Wir", die wir im Trümmerfeld der Geschichte lediglich eine "Kette von Begebenheiten" sehen, sind nämlich treue Schüler jenes Historismus, der sich damit begnügt, “einen Kausalnexus von verschiedenen Momenten der Geschichte $\mathrm{zu}$ etablieren" und "die Abfolge der Begebenheiten durch die Finger laufen zu lassen wie einen Rosenkranz"

Historistische Diachronie und strukturalistische Synchronie, die sonst immer gegeneinander ausgespielt werden, gehören hier so eng zusammen wie die zwei Instanzen - historischer Materialismus und jüdische Theologie -, die bei Benjamin über sie Gericht halten. ${ }^{88}$ Sowenig seine Sprachtheologie die bürgerliche Zeichentheorie tolerieren kann, sowenig duldet seine materialistische Geschichtsphilo- sophie den bürgerlichen Historismus. Seine Anklage lautet in beiden Fällen: Verschweigen der Katastrophe. Eine subjektive Wissenschaft, die streng objektiv zu sein meint, drückt dem realen Chaos ihre terminologische Ordnung auf und verdoppelt damit die Willkür, an der ihr Gegenstand schon leidet. Sie räumt die Spuren schön ordentlich weg, indem sie den "Zeit-Raum" des Sündenfalls nochmals verräumlicht Das geschieht entweder durch einen synchronen Querschnitt oder durch eine diachrone Übersicht. Aber der strukturalistische Querschnitt schafft seinerseits eine Übersicht, und der historistische Überblick ist umgekehrt ein Längsschnitt. Wer mit Ranke das Panorama der Vergangenheit überblicken will 'wie es eigentlich gewesen ist' ${ }^{\prime 89}$, nimmt die gottähnliche Perspektive eines allwissenden Erzählers ein. Die Diachronie schrumpft dabei zur Synchronie zusammen, die bei den Strukturalisten ebenfalls einem quasi göttlichen Blickwinkel entspricht. ${ }^{90}$ Aber diese komplementären Perspektiven entspringen in Wirklichkeit dem Sündenfall. Die Verräumlichung der Zeit, die den wissenschaftlichen Überblick ermöglicht, hat ihre Vorgeschichte im "Zeit-Raum" des deutschen Trauerspiels. Die Wahrheit der barocken Aussicht auf die "erstarrte Urlandschaft" ${ }^{1}$ der "NaturGeschichte" geht jedoch in dem Augenblick verloren, wo die Trauer des Allegorikers durch die Neutralität einer affektleeren, wertfreien Wissenschaft ersetzt wird.

Die wissenschaftliche These vom arbitraire du signe erwies sich vorhin als ein weiteres Symptom jener Willkür, die Benjamin zufolge nur aus sprachtheologischer Perspektive zu diagnostizieren ist. Aber sie braucht sich lediglich beim Wort zu nehmen, um die Diagnose selber zu stellen. Sie weiß es nicht, so wäre das Marxsche Wort abzuwandeln, aber sie sagt es. Ähnliches gilt für das Verhältnis des Historismus zum historischen Materialismus. Die gefährdete Vogelperspektive des angelus novus ist die Sichtweise eines zu sich gekommenen Historismus. ${ }^{92}$ Liefert letzterer "das ewige Bild der Vergangenheit" 93 , so stellt die Geschichte in den Augen des Engels eine permanente Katastrophe dar. Nicht, daß er sie im gleichen Sinn sub specie aeternitatis betrachtet. Da er im nächsten Augenblick 
vom Sturm des Fortschritts fortgetrieben werden wird, ist er kaum in der Lage, die Illusion des Historismus zu teilen, die Wahrheit könne ihm "nicht davonlaufen"94. Auch von seiner prekären Warte ${ }^{95}$ aus gesehen fallen jedoch Synchronie und Diachronie zusammen. Der strukturalistische Querschnitt, der die Diachronie nicht mehr passieren läßt, wird hier zur "messianischen Stillstellung des Geschehens"96, die das falsche Kontinuum der Geschichte erstarren läßt, indem sie ihr Medusenhaupt apotropäisch gegen sie kehrt. Vor den Augen des angelus novus schrumpft die Weltgeschichte zum nackten Grauen zusammen, das den Schleier der - mechanischen - Chronologie zerreißt. Die "Kette von Begebenheiten", die uns den Blick versperrt, stellt sich nunmehr als die mythische Verkettung eines Schuldzusammenhangs, ihr unschuldiges Nacheinander als ein heilloses Durcheinander, dar. Indem der historistische Überblick sich selber überhöht, wird er zum wahren Ausblick auf den Zeit-Raum der Geschichte. Dem Engel der Geschichte ist alles ungleich drastischer "unmittelbar" als dem komfortablen Gott des Historismus. Er erfährt am eigenen himmlischen Leibe, "wie es denn eigentlich gewesen ist". Die "Universalgeschichte", deren sich der Historismus befleißigt, ist nämlich bisher kein "Triumphzug" ${ }^{97}$, sondern ein einziger Trauerzug gewesen ist. ${ }^{98}$

"In Gottes Welt", heißt es am Ende des Trauerspielbuchs, "erwacht der Allegoriker"99. Verkehrt sich dort der Sturz des bösen Engels mit "einem Umschwung"100 in eine erlösende Gegenbewegung, so findet sich umgekehrt der angelus novus, der kein gefallener Engel ist, in der Hölle wieder. Nicht aus dem Traum, sondern mitten drin ist er erwacht. Er könnte in diesem Sinne ein erwachter Historist, ein zu sich gekommener, aber keineswegs geretteter Allegoriker genannt werden. Der "subjektive Blick der Melancholie" 101 , der dem Allegoriker eigen ist, und die entsprechende "Traurigkeit" 102 des Historisten sind einer objektiven Trauer gewichen. Während der Historismus die selbstbefangene Willkür ${ }^{103}$ darstellt, die sich hinter einer Fassade erhabener Objektivität verbirgt, verkörpert der fast körperlose Engel das unglückliche Bewußtsein der objektiven Willkür - der um sich greifenden Subjektivität -, die sich auf dem Trümmerfeld der Weltgeschichte austobt. Beide erinnern also auf je verschiedene Weise an die Optik des barocken Allegorikers. Der Engel, der die "facies hippocratica der Geschichte" ${ }^{104}$ mit weit offenen Augen betrachtet, erkennt sie als den Alptraum, aus dem er aufwachen möchte. Demgegenüber träumt der schlafwandelnde Historismus die "letzte Phantasmagorie des Objektiven" 105 weiter und macht's dabei dem Allegoriker ebenfalls nach, der "im Sündenfall zu Hause ist"106. Es ist kein Zufall, wenn Benjamins Beschreibung des Historismus als eines "Bordell[s]", wo man sich bei der "Hure 'Es war einmal""107 ausgibt, an die Stelle im Trauerspielbuch anklingt, wo die Willkür allegorischen Bedeutens als "finsterer Sultan" personifiziert wird, der "im Harem der Dinge" 108 herrscht. Die Genauigkeit der Parallele zwischen diesen allegorischen Darstellungen der allegorischen Verhaltensweise verweist auf einen grundlegenden Zusammenhang.

"Die Erinnerung des Grüblers", notiert Benjamin im Passagen-Werk,

verfügt über die ungeordnete Masse des toten Wissens. Ihm ist das menschliche Wissen Stückwerk in einem besonders prägnanten Sinn: nämlich wie der Haufen willkürlich geschnittener Stücke, aus denen man ein puzzle zusammensetzt. [...] Der Allegoriker greift bald da bald dort aus dem wüsten Fundus, den sein Wissen ihm zur Verfügung stellt, ein Stück heraus, hält es neben ein anderes und versucht, ob sie zu einander passen: jene Bedeutung zu diesem Bild oder dieses Bild zu jener Bedeutung. ${ }^{109}$

Dasselbe galt vorhin - im eingangs zitierten Brief an Hofmannsthal - für das erratische Verhalten der irrenden Einzelwissenschaften, die "bald hier bald da" im Sprachbereiche 
sich behelfen. An der Willkür seines Zugriffs ist das gefallene Wissen zu erkennen. ${ }^{110}$ Nicht anders verhält sich der Historismus, der beliebige Fakten aus dem wüsten Fundus seines Wissens stückweise herauskramt. ${ }^{111}$ Solche Geschichtsschreibung, heißt es an anderer Stelle weiter,

hat denn auch von jeher aus dem kontinuierlichen Verlauf einen Gegenstand einfach herausgegriffen. Aber das geschah ohne Grundsatz, als Notbehelf; und ihr erstes war denn auch immer, den Gegenstand ins Kontinuum wieder einzubetten [...]. Die materialistische Geschichtsschreibung [...] greift nicht, sondern sprengt sie aus dem Verlauf heraus. ${ }^{112}$

Während der Engel der Geschichte das Zerschlagene gern zusammenfügen würde, zerschlägt's der Historismus noch einmal, um anschließend solche potenzierte Willkür als ihr Heilmittel auszugeben. Das doppelte Stückwerk wird zur Phantasmagorie eines organischen Ganzen zusammengefügt. Der vorwärtsgetriebene Engel möchte beim Zerschlagenen "wohl verweilen". Der saturierte Historist schlendert hingegen wie ein "Müßiggänger im Garten des Wissens"113 herum, um eine müßige Ordnung aus der ungeordneten Masse seines toten Wissens zusammenzustellen. Jener Garten ist lediglich ein Zerrbild des längst verlorenen Paradieses. Wer in ihm lustwandelt, will vergessen, daß er in der Wüste irrt. So wie die gefallenen Zeichen eine "Parodie" der paradiesischen Namenssprache lieferten, so karikiert das gefallene Wissen des Historismus die "messianische Idee der Universalgeschichte"114.

Dieselbe Antithetik, die die Einsicht des Engels von der Blindheit des Historismus trennt, unterscheidet das geschärfte Bewußtsein, das der Allegoriker vom "Abgrund zwischen bildlichem Sein und Bedeuten" hat, von der "unbeteiligten Süffisanz, die in der scheinbar verwandten Intention des Zeichens sich findet"115. Ein Abgrund zwischen Zeichen und Bezeichnetem hatte sich im Sündenfall erstmals aufgetan, als die Sprache sich selber fremd geworden war. Von da an sollte das Wort "etwas mitteilen (außer sich selbst)"116. Damit war im Ansatz die weitere Kluft gegeben, die in der Allegorie Bild und Bedeutung trennt. Alles kommt seitdem darauf an, ob die Menschen sich im Abgrund häuslich einrichten oder aber das schmerzliche Bewußtsein der Entfremdung wachhalten. Beide Möglichkeiten sind von vornherein gegeben. Entweder gedenkt der erwachende Allegoriker des weltgeschichtlichen Ursprungs, der seiner "Trauer Einsatz und Ausgang zugleich weist"117, oder er verliert mit dem Bewußtsein des Unheils die Perspektive der Erlösung. Im zweiten Fall wird der allegorische Weltzustand verschleiert, indem er nochmals allegorisiert wird. Allegorie der Allegorie - eine solche Formel, die man der Schlegelsehen "Ironie der Ironie"118 an die Seite stellen könnte, hätte in diesem Zusammenhang einen doppelten Sinn. Man kann darunter entweder die schlechte Unendlichkeit oder aber das gute Ende der Allegorie verstehen. Entweder bedeutet die Allegorie, zu deren Definition es gehört, von etwas anderem (allos) zu reden, ihrerseits etwas anderes als sie ist, und zwar das "Nichtsein" dessen, was sie "vorstellt"119. Damit ginge das Nichts des Bösen - wie am Ende des Trauerspielbuchs - im Sein des Guten unter. Die Allegorie wäre eine präfigurative Figur, die ihr Ende in sich trägt. Oder aber sie potenziert sich selber, geht immer so weiter, und hebt sich damit auf andere, falsche Weise auf. Das Subjekt hätte sich nunmehr seiner Entfremdung so weit entfremdet, daß es diese seine doppelte Leere für "gesättigtes Sein"120 halten könnte. Dieses Schema, das später von der Frankfurter Schule auf die Eindimensionalität der spätbürgerlichen Konsumgesellschaft übertragen worden ist, gilt zunächst bei Benjamin für den wissenschaftlichen Komfort sowohl der bürgerlichen Zeichentheorie als auch des Historismus. Ihre gemeinsame Ursünde wurde vorhin als ein Vergessen des Vergessens 
bezeichnet. Die Semiologie, die die Sprache in ein formales System reiner Differenzen aufteilt, vergißt darüber die große ontologische Differenz, die zwischen einer unmittelbaren Namenssprache und einer Sprache prädikativer Ur-teile und kommunikativer Mit-teilung besteht. Und der Historiker, der sich an die Fakten verliert, übersieht dabei die eine Katastrophe, die aus ihnen herauszulesen ist. Beide sind schlechte, selbstvergessene Allegoriker, die dem Abgrund umso hoffnungsloser verfallen, je weniger sie von ihm wissen wollen.

50 Fassen wir unseren Kommentar zusammen. Der Sturm des Fortschritts, der Benjamins angelus novus vorwärtstreibt, erscheint gegen den Hintergrund seiner frühen Sprachphilosophie als eine schreckliche Parodie auf das göttliche "Einblasen des Odems", das dem ersten Menschen Leben, Geist und Sprache verlieh. An die Stelle der inspirierten Namen tritt im Sündenfall die Inflation der Zeichen. Was wir den Fortschritt nennen, wäre nichts anderes als dieses windige "Geschwätz". Flatus vocis hatten die Nominalisten den mittelalterlichen Begriffsrealismus abwertend genannt. Ihre Wiederaufnahme einer konventionalistischen Sprachtheorie ging mit der vielgerühmten Emanzipation des bürgerlichen Individuums einher. Diese epochale Wende wird beim frühen Benjamin von einer sprachphilosophisch gedeuteten Version des Sündenfalls überblendet. Wem Namen Schall und Rauch, und Universalien will- kürliche Spielmarken, ${ }^{121}$ sind, der läßt Schutt und Trümmer hinter sich. Philosophiegeschichtlich betrachtet wäre der Sturm des Fortschritts der losgelassene Nominalismus, dessen eigener flatus vocis am Ende die haecceitas verwüstet, die er ursprünglich gegen den mittelalterlichen Realismus geltend machte. In der "Erkenntniskritischen Vorrede" zum Trauerspielbuch wird deshalb nicht der Nominalismus, sondern ein adamitischer Platonismus mit der "Rettung" des "Einzelnen" 122 beauftragt - ein philosophiegeschichtlicher Anachronismus, der zugleich den aktuellen Impuls der damaligen Philosophie teilt, "zu den Sachen selbst" zurückzukehren. Benjamins "Platonismus" ist ebenfalls - über alle Differenzen oder Korrektive hinweg - seinem späteren "historischen Materialismus" wahlverwandt. Die Sehnsucht nach der himmlischen Ruhe einer entrückten Namens- und Ideensphäre, ${ }^{123}$ die den Verkehr der Zeichensprachen noch nicht oder nicht mehr kennt, ist mit dem revolutionären Impuls zusammenzudenken, eine messianische "Stillstellung des Geschehens"124 im Sinne eines Generalstreiks herbeizuführen. Wenn der Fortschritt zur unkontrollierbaren Dynamik einer Naturkatastrophe geworden ist, dann kann die Revolution nicht mehr als die "Lokomotive" der geschichtlichen Dialektik, sondern nur noch als "Griff [...] nach der Notbremse" 125 oder als "Um- kehr" 126 gedacht werden. Benjamins Geschichtsphilosphie kehrt mit dieser Feststellung $\mathrm{zu}$ ihren sprachphilosophischen Anfängen zurück.

51 Seine allegorische Deutung des Kleeschen Engels läßt sich in diesem Zusammenhang als die geschichtsphilosophische Variation eines sprachphilosophischen Paradigmas verstehen, das seinerseits auf die biblische Genesis-Geschichte zurückgeht. Die Geschichte, die sie erzählt, läßt Geschichte überhaupt mit dem Sündenfall des Sprachgeistes anfangen. Erzählen wir ein letztes Mal diese folgenreiche Geschichte nach. Im Sündenfall tritt der Name aus der "immanenten eigenen Magie" heraus, "um ausdrücklich, von außen gleichsam, magisch zu werden" ${ }^{127}$. Was wir sonst Säkularisierung nennen, ist demzufolge Dämonie. Mit der Profanierung der Sprache entsteht eine "ausdrückliche" Magie, die den Dingen ihre "verantwortungslose Willkür aufprägt”. Äußerlichkeit, Schrift, und eine Art schwarzer Magie fallen mit dem Anbruch dieser Willkürherrschaft zusammen. Daraus resultiert eine nicht enden wollende 
"Narretei". Die selbstbezogene Zeichensprache, die kein fundamentum in re mehr hat, erzeugt einen phantasmagorischen Beziehungswahn, der jeden echten Bezugs zur Wirklichkeit entbehrt. Deshalb wirkt er so tödlich auf sie ein. Aber der Fluch, den er über sie ausbreitet, hat einen doppeldeutigen Charakter. Er ist zugleich das Wirklichste und das Unwirklichste von der Welt. "Nur um ein Geringes" wird der Messias eine "entstellte" Welt "zurechtstellen" 128 müssen, weil das Böse selber ein bloßes "Nichts" ${ }_{129}$ ist. Aber das Nichts droht zugleich die Welt zu vernichten. Das ist die theologische Dialektik von Sein und Nichts, der Doppelboden eines grundlosen - d.h. bodenlosen oder aber inexistenten Abgrunds, die Paradoxie eines Sturms, der dem schlechten "Odem" des Geschwätzes entspringt.

Das windige Geschwätz einer "leeren Subjektivität"130 bläst durch eine "homogene und leere Zeit"131 hindurch. So sieht rückblickend der Motor des Fortschritts aus. Es ist, als hätte die Geschichte im Augenblick des Sündenfalls zu ticken angefangen. ${ }^{132}$ Die schlechte Unendlichkeit der Zeichen zeitigt die abgründige Zeitstruktur, die dem Marsch des Fortschritts zugrundeliegt. Ist der Name, der die Dinge ein für allemal nennt, in der vollendeten Zeit zu Hause, so entspricht das Zeichen, das sie überbenennt, einer höllischen Zeit, die "immer wieder von vorn" anfängt ${ }^{133}$. Die "ewige Wiederkunft" ${ }^{134}$ von Zeichen und Sekunden stellt eine höllische Parodie auf den Kreislauf des Logos dar. An die Stelle des ewig in sich kreisenden Worts tritt eine lineare Logik eiserner Konsequenzen, deren fortschreitende Geschichte sich ihrerseits im Kreise dreht. Fortschritt ist von Schicksal, die Kette der Ereignisse von mythischer Verkettung, nicht mehr zu unterscheiden. Seit dem Sündenfall ist alles, was vorfällt, dessen "unausbleibliche Folge"135. Die Chronologie der Natur-Geschichte steht unter dem Zeichen Saturns, der - wie Chronos - seine Kinder frißt. Sind Sprache und Zeit einmal aus ihrer vollendeten Immanenz herausgetreten, dann kennen sie nur noch die beliebige Pünktlichkeit, die quantitative Ausdehnung, einer langwierigen, langweiligen Katastrophe. Seitdem die ersten Menschen infolge ihrer Abkehr von den Dingen aus dem Paradies vertrieben wurden, beschäftigen sie sich damit, die Zeit zu vertreiben, indem sie sie zur weiteren Zerstreuung mit sinnlosen Bedeutungen vollstopfen. Geschichte wäre insofern - nach Theodor Lessings Formel - "Sinngebung des Sinnlosen", als solcher Sinn Benjamins Sprachphilosophie zufolge - mit der Sinnleere zusammenfällt, die er übertönen will. Bietet der spleen bei Baudelaire "den Schwarm der Sekunden" gegen "die Kraft des Eingedenkens" auf ${ }^{136}$, so bietet seinerseits der Historismus, der ebenfalls an "acedia"137 leidet, "die Masse der Fakten auf, um die homogene und leere Zeit auszufüllen"138. So geht die Apokalypse beliebig weiter, die kein Ende nehmen will, weil sie kein Telos hat. Das sprachphilosophische Paradigma, welches Zeichen, Willkür, Mittel, Urteil, Abstraktion, Bedeutung und Geschwätz im Sündenfall des Worts zusammenfallen läßt, wird um eine geschichtsphilosophische Konstruktion ergänzt, die ihrerseits die Geschichte mit dem Fortschritt des Sündenfalls, mit permanenter Katastrophe und ewiger Wiederkunft, mit Vergessen und Langeweile gleichsetzt.

Die Geburt der Geschichte aus dem Sündenfall des Sprachgeistes - man mag davon halten, was man will. Wie muß aber die Geschichte aussehen, damit man auf eine solche Idee verfällt? 


\title{
IV. Benjamins Geschichtsphilosophie als moderner Antimodernismus?
}

\author{
"Das ist Theologie; aber im Eingedenken machen \\ wir eine Erfahrung, die uns verbietet, die \\ Geschichte grundsätzlich atheologisch zu \\ begreifen, so wenig wir sie in unmittelbar \\ theologischen Begriffen zu schreiben versuchen \\ dürfen".
}

Ihre Ableitung aus dem Sündenfall läßt die Geschichte nur noch als Natur-, Ur- und Vorgeschichte, und damit schon als post-histoire erscheinen. Mit der Modeme einsetzend, setzt sie sich unentwegt mit der sogenannten Postmodeme fort. "Soviel Bedeutung, soviel Todverfallenheit": soviel neue Termini, soviel zusätzliche Willkür. Was der Engel der Geschichte vor sich sieht, schließt die Zukunft ein, von der er sich abwendet. Im Zeitalter der Autofriedhöfe, des Atommülls und der neuen Leichenberge bleibt das allegorische Denkbild des Trümmerhaufens allzu unverjährt. Da aber der Sturm, der die Trümmer hinterläßt, aus dem "Vergessen" herweht, stand zu erwarten, daß das geschichtstheologische Eingedenken das jenen Anblick festhielt, selber früher oder später auf dem geschichtlichen Trümmerhaufen landen würde. Das stumme Grauen des neuen Engels ist zwar mit keinerlei philosophischem Staunen zu verwechsein. ${ }^{139}$ Aber es ist bei aller Sprachlosigkeit eine eminent sprach- und geschichtsphilosophische Angelegenheit.

An der Geschichtsphilosophie ist jedoch inzwischen allerorten ein wachsendes Unbehagen angemeldet worden. Einen instruktiven deutschen Beleg für diesen internationalen Trend liefert Odo Marquards Aufsatzsammlung Schwierigkeiten mit der Geschichtsphilosophie ${ }^{140}$. In einem jüngst erschienenen Aufsatz "Die arbeitslose Angst. Antimodernismus in der postmodernen Gesellschaft" ${ }^{141}$, der als ein weiteres Zeichen der Zeit hier kurz berücksichtigt werden soll, unterscheidet Marquard drei Grundformen der neueren Geschichtsphilosophie - eine "promodernistische Variante" (Hegel), eine "präterital antimodernistische" (Rousseau) und eine "futural antimodernistische" (Marx) - und stellt folgende These auf:

Die gegenwärtigen westlichen und speziell bundesrepublikanischen Revolten gegen das Bestehende - also etwa Stundentenbewegung, Friedensbewegung, grüne Welle - sind Fortsetzungen des Antimodernismus unter Verwendung der Zukunft und schließlich der Natur als Mittel: sie stehen in einer Tradition, die man die Tradition des futurisierten Antimodernismus nennen kann.

Antimodernismus - ein Begriff, der bezeichnenderweise der jüngsten Kirchengeschichte entstamme - sei die paradoxe Signatur einer heute wieder grassierenden romantischrevolutionären Geschichtsphilosophie, die die Gegenwart als "das Zeitalter des Verfalls durch Fortschritt" bestimme. Diese "Hölle auf Erden" werde im Namen einer vergangenen heilen Welt oder einer künftigen Utopie verurteilt.

Der Aufstieg dieses Antimodernismus von der Zukunft her bis zur puren Selbstverständlichkeit erfolgt vom 19. ins 20. Jahrhundert hinein: z.B. durch Aufnahme des Marxismus nun auch ins theologische Denken, das antimodernistisch bleibt, obwohl es jetzt nicht mehr die Vergangenheit sondern die Zukunft anbetet. Das ist jener Vorgang, den ich nenne: die Futurisierung des Antimodernismus: durch ihn kommt endgültig heraus, was die Geschichtsphilosophie grundsätzlich ist: Antimodernismus. 

genommen könnte die stumme Klage der Natur den Eindruck erwecken, ihr Fürsprecher sehne sich nach guten alten vortechnologischen Zeiten zurück. Der Protest gegen die Instrumentalisierung der Natur würde sie dann ihrerseits im Sinne Marquards als Mittel mißbrauchen, um Technik als solche zu diffamieren. Benjamins Beschwörung einer trauernden Natur, die in den "Abgrund der Mittelbarkeit" ${ }^{143}$ gestürzt worden sei, muß jedoch im Zusammenhang mit anderen Motiven gelesen werden, wo die Technik als Hebamme aufgefaßt wird, welche die Kräfte der Natur entbindet. ${ }^{144}$ Läßt sich - um ein weiteres Beispiel zu nennen - der "Verfall der Aura" tatsächlich auf den "Verfall des seligen Sprachgeistes" zurückführen, so wird später im Namen eines echten, revolutionären Fortschritts, der aus der Verfallsgeschichte herausführen könnte, der "Zertrümmerung der Aura"145 das Wort geredet. Zwar würde der Engel der Geschichte lieber aus der Geschichte nach Hause zurückkehren. Aber Benjamins Geschichtsphilosophie ist auch hier nicht auf eine Verfallstheorie zu reduzieren. Die "Umkehr", die dem falschen Fortschritt den Rücken kehrt, soll die Kehrseite des echten sein. Ein solches Schema könnte bei Marquard allenfalls als die mehr oder weniger geglückte Verbindung einer "präterital" mit einer "futural" antimodernistischen Geschichtsphilosophie eingestuft werden. Was wäre aber damit gewonnen? Wie, wenn das neudeutsche Begriffsraster einer solchen Diskursanalyse eine Neuauflage des historisch-strukturalistischen Panoptikons wäre? Ist die Verabschiedung der Geschichtsphilosophie wirklich die vordringlichste Aufgabe? Wissen nicht die wildesten Ökologiefreaks, die zumindest den Trümmerhaufen nicht aus den Augen verlieren, da besser Bescheid?

Inwieweit die verschiedenen geschichtsphilosophischen Motive, von denen nur eines hier zur Diskussion stand, sich bei Benjamin zu einem kohärenten Ganzen zusammenfügen lassen, wäre einer Untersuchung wert. ${ }^{146}$ Soviel scheint jedoch jetzt schon festzustehen: Benjamins bruchstückhafte Geschichtsphilosophie ist kaum in gängige Schemata hineinzuzwingen. Wo Marquard die positiven Errungenschaften der Modeme mit unanfechtbarer Ausgewogenheit gegen die "neue Negativierung der modernen Welt" ausspielt, setzt Benjamin auf die wahlverwandte Radikalität positiver und negativer Extreme. Bestehende - und künftige - Antinomien werden dabei stillschweigend abgebaut. Ein messianischer Elan, der vielleicht am ehesten mit dem dithyrambischen Jasagen eines Nietzsche zu vergleichen wäre, paart sich mit einer destruktiven Energie, die ihrerseits zu messianisch ist, um sich von der Trägheit des Bestehenden entkräften zu lassen. Ist eine Auseinandersetzung zwischen Benjamins emphatischen Impulsen, die kaum mit sich reden lassen, und Marquards ausgemachter Skepsis, die sich überall bestätigt findet, überhaupt denkbar? Oder werden beide Positionen durch einander lediglich provoziert? 
61 Der Umgang mit der Geschichtsphilosophie - davon zeugte schon die Sprachlosigkeit des Benjaminsehen Engels - ist heute schwieriger geworden. Aber ihre voreilige Verabschiedung - das weiß auch Marquard auf seine Art ${ }^{147}$ - ist nicht minder problematisch. ${ }^{148}$ So widersprüchlich ein Antimodemismus sein mag, der von der Modeme zehrt, Benjamin wußte, daß es Widersprüche gibt, denen enthoben zu sein man "nicht einmal im Traum wünschen" kann"149. "Die ausgebildetste Zivilisation und die modernste Kultur", schrieb er 1931 an Scholem,

gehören nicht nur zu meinem privaten Komfort, sondern sie sind zum Teil geradezu Mittel meiner Produktion. [...] Aber willst du mir wirklich verwehren, mit meiner kleinen Schreibfabrik, die da mitten im Westen liegt, ganz einfach aus dem gebieterischen Bedürfnis, von einer Nachbarschaft, die ich, aus Gründen, hinzunehmen habe, mich zu unterscheiden - willst du mir mit dem Hinweis, das sei ja nichts als ein Fetzen Tuch, verwehren, die rote Fahne zum Fenster herauszuhängen? ${ }^{150}$

\title{
V. Schluss
}

\author{
"Es ist, als wäre ich in eine Festzeit eingetreten \\ und ich muß in dem was sich Ihnen eröffnet hat \\ die Offenbarung verehren. Denn es ist doch nicht \\ anders daß das was Ihnen zugekommen ist Ihnen \\ allein eben an Sie gerichtet worden sein muß und \\ wieder für einen Augenblick in unser Leben \\ getreten ist"151 \\ Benjamin an Scholem, 1917 \\ “denn wirklich, im Innersten, Verborgnen geht es \\ nicht so weiter sondern von einem Extrem ins \\ andere" 152
}

Sein Hinweis auf die sprachtheologische "Überzeugung", die ihn in seinen literarischen Versuchen leite, kann - so unsere These - nicht ernst genug genommen werden. Es gibt in seinen Schriften keine Zeile, die nicht von ihr getragen wäre. Gewiß, ein

antikonventionalistisches Vorurteil wurde immer schon gerade von solchen erleuchteter, "konstatierontologischer" Aussagen mehr zu. Um sicher zu sein, wie es “wirklich, im Innersten, Verborgnen" zugeht, muß man - wie der Allegoriker am Ende des Trauerspielbuchs - erfahren haben, daß Willkür nicht das letzte, sondern nur das vorletzte Wort haben kann. "Gänzlich auf sich selbst gestellt", fand sich jener "nicht mehr spielerisch in erdhafter Dingwelt sondern ernsthaft unterm Himmel" wieder ${ }^{153}$. Zwischen diesem Himmel, unter dem der Allegoriker "zur Auferstehung treulos überspringt", und dem "freie[n] Himmel der Geschichte", unter dem der "Sprung" der "Revolution" - noch 1940 - stattfinden kann, ${ }^{154}$ besteht eine weitreichende Kontinuität. Walter Benjamin stellt den reinen - und in diesem Jahrhundert vielleicht einzigartigen Fall eines solchen tragenden theologisch-politischen Urvertrauens dar. Ob diese exterritoriale, "gänzlich auf sich selbst gestellte" Grundhaltung eher dazu prädestiniert ist, Offenbarungen zu empfangen, als Einsichten zu verdrängen, das ist die große Frage. Sie ist womöglich die heutige Gestalt der Gretchenfrage. Benjamin mit psychologischen Argumenten beizukommen, ist indessen schwierig. Geht er doch davon aus, das Unwillkürliche auf seiner Seite zu haben.

Anthropology \& Materialism, Special Issue | I | 2017 
Schriftstellern gehegt, die zu ihrer Muse hielten. ${ }^{155}$ Benjamins Überzeugung ist nicht jedoch als die arbeitsteilige Lebenslüge eines freien Schriftstellers abzutun. Sie ist vielmehr für seine intellektuelle Haltung und seine biographischen Entscheidungen durch sämtliche Phasen hindurch bestimmend gewesen. Worum es hier geht, ist gerade ein - bestimmtes - Ethos der Bestimmung: das unwillkürliche Verhältnis, welches gewisse Einsichten mit "ganz bestimmten" Worten, gewisse Augenblicke und Epochen mit "ganz bestimmten früheren" im "Innersten, Verborgnen" miteinander unterhalten. Es geht darum, der empfängliche Adressat einer an keinen anderen als einen selbst ergangenen ("Ihnen allein eben an Sie gerichtet") Stimme zu sein. Ließ Benjamin seine eigene Bestimmung zum Gegenstand scharfer Auseinandersetzungen mit ausgewählten Freunden werden, so stand doch beinahe für alle Beteiligten fest, daß es diese Bestimmung gab. Und wenn sein Leben zu einem von seinen eigentlichen Zielen abgelenkten Leidensweg, zum Zickzack des Vertriebenen werden sollte, so bestand für ihn dennoch kein Zweifel, daß er einen jeweils bestimmten Weg zu gehen hatte. Seinem sprachphilosophischen Selbstverständnis nach hatte der Weg dieses unbeirrten Flaneurs einen ursprünglichen Sinn, der - diesseits des fatalen Gegensatzes zwischen Sinn und Sinnlosigkeit - im Palast der Sprache angesiedelt war. Auch wenn das Lauschen einer erschütterten Tradition seiner Kafka-Deutung zufolge nur noch "Undeutlichstes" ausmachen konnte ${ }^{156}$, so drang doch mehr bei Benjamin als bei Kafka von der "kaiserlichen Botschaft" 157 durch. Er war zum Beispiel davon überzeugt, daß auch der sogenannte Fortschritt nicht "so weiter" geht, sondern "von einem Extrem ins andere". "Zum Begriff der Rettung", notierte er in seinen späten Aufzeichnungen: "der Wind des Absoluten in den Segeln des Begriffs"158. Hat nicht sogar der Engel der Geschichte mitten im Sturm des Fortschritts etwas von diesem Wind in seinen schriftrollartigen Flügeln? Denn erstens gibt es den Engelsboten noch, und zweitens verzweifelt er zumindest nicht an den Fundamenten seiner Verzweiflung. Noch in der "abgestumpften" 159 Nüchternheit ${ }^{160}$ seines materialistischen Spätstils hallt Benjamins altes metaphysisches Pathos nach. Und dieses Pathos fällt mit seiner Verurteilung jeglicher Willkür strikt zusammen.

Die produktive Rolle, die die These vom arbitraire du signe bei der Erneuerung ganzer Disziplinen und der Kritik gängiger Ideologien ${ }^{161}$ seither gespielt hat, zeigt freilich an, daß der Begriff der Willkür keiner ist, der sich von selbst erledigt. Die Frage ist vielmehr, ob Benjamins summarische Abfertigung der Willkür-These ihrerseits ebenso summarisch zu verabschieden ist. Etwa - wie man es sich bei Gerard Genette vorstellen könnte - als eine reichlich verspätete Episode innerhalb der ehrwürdigen, harmlosen, ebenso unterhaltsamen wie unwissenschaftlichen Geschichte eines offenbar unausrottbaren "Kratylismus". Hat Benjamin einen Dichterglauben, eine Dichterlüge zu seinem Credo gemacht? Greift seine Ablehnung der Willkür-These? Kann seine Sprachphilosophie ihren wissenschaftlichen Anspruch rechtfertigen? Ist der Posten wirklich ein verlorener? Adorno bemerkte einmal, daß die Debatte zwischen Kratylos und Hermegenes noch offensteht. Vorliegener Beitrag versteht sich als eine kleine Vorarbeit zu iher Wiederaufnahme. 


\section{ENDNOTES}

1. Walter Benjamin, Gesammelte Schriften, (hiernach GS), hrsg. v. Rolf Tiedemann und Hermann Schweppenhäuser (Frankfurt a. M.: 1974 ff.), Bd. I.1., S. 48.

2. Walter Benjamin, Briefe, (hiernach B), hrsg. v. Gershom Scholem und Theodor W. Adorno (Frankfurt a. M.: 1966), S. 425. Vgl. dazu Verf., “'Immer radikal, niemals konsequent ...'. Zur theologisch-politischen Standortbestimmung Walter Benjamins”, in: Antike und Moderne. Zu Walter Benjamins 'Passagen', hrsg. v. Norbert W. Bolz und Richard Faber (Würzburg, 1986), S. 116-137.

3.

4.

5.

6. GS, I.1, S. 47.

7. GS, I.1, S. 50.

8. Die Verschiedenheit dieser theoretischen Idiome untereinander wird von Benjamin kaum reflektiert. Ließe sie sich im Ernst unter Hinweis auf die Sprachzersplitterung erklären, die einem jener Idiome zufolge auf den Sündenfall zurückzuführen ist?

9. Vgl. jedoch $\mathrm{zu}$ Saussures eigener Position: Jean Starobinski, Les mots sous les mots. Les anagrammes de Ferdinand de Saussure (Paris, 1971); und Gérard Genette, Mimologiques. Voyages en Cratylie (Paris, 1976), S. 414-416. Saussure kommt bei Benjamin an einer einzigen, nichtssagenden Stelle vor (GS, III., S. 468).

10. GS, II.1, S. 207. "Für Einsichtige" wird in der überarbeiteten Fassung "Über das mimetische Vermögen" gestrichen. Vgl. dazu Scholems Bemerkung, daß die theologische Inspiration seiner Texte ihre besondere Form begründet, "die so viele wichtige Sätze Benjamins [...] mit der Aura des ex cathedra umkleidet. Seine Feinde sprachen schon früh von der 'Konstatierontologie' in seinen Schriften. [...] Seine Sätze haben oft genug die autoritäre Haltung von Offenbarungsworten [...]" (Walter Benjamin und sein Engel (Frankfurt a. M., 1983), S. 35). Benjamins charakteristischer Sprachgestus geht in der Tat aus seiner Sprachtheologie stringent hervor. Sein bedingter Anspruch auf Absolutheit wird gleich im ersten Abschnitt des Trauerspielbuchs sorgfältig begründet, wo die Notwendigkeit einer relativen "Esoterik" relativ exoterisch dargelegt wird. (Vgl. GS, I.1, S. 207-209, und auch GS, IV.2, S. 906)

11. B, 1, S. 329.

12. Benjamins "Lehre vom Ähnlichen" geht in diesem Sinne von einer Auffassung der Sprache aus, die "mystischen oder theologischen Sprachtheorien engstens verwandt" ist, "ohne darum jedoch empirischer Philologie fremd zu sein" (GS, II.1, S.208).

13. "Die Einführung neuer Terminologien", heißt es in der "Erkenntniskritischen Vorrede" zum Trauerspielbuch, "[...] ist [...] bedenklich. Solche Terminologien - ein mißglücktes Benennen, an welchem das Meinen mehr Anteil hat als die Sprache - entraten der Objektivität, welche die Geschichte den Hauptprägungen der philosophischen Betrachtungen gegeben hat" (GS, I.1, S. 217).

14. Eine solche Entstellung der Entstellung könnte als der messianische Ruck gedeutet werden, der die Wahrheit der Sprache wiederherstellt. Der Messias wird dem Kafka-Aufsatz zufolge die “ entstellte" Welt "nur um ein Geringes [...] zurechtstellen" müssen (GS, II.2, S. 432). 
15. Zwei Fragen drängen sich in diesem Zusammenhang auf. 1. Wie, wenn der sprachwissenschaftliche Begriff der Willkür seine semantische Vorgeschichte keineswegs leugnet, und deshalb keine willkürliche, zufällige Wortwahl darstellt? Vgl. dazu den aufschlußreichen Aufsatz "Saussure, Je signe et la democratie" von Roland Barthes, in: L'Aventure sémiologique (Paris, 1984), S. 221-226, der die "bürgerlichen" Implikate einer konventionalistischen Semiologie auf andere Weise sichtbar macht. 2. Inwieweit bleibt Benjamins eigener Umgang mit der Idee der Willkür der historischen Philologie treu, der er hier das Wort zu reden scheint? Schlägt man in Grimms Wörterbuch nach, um etwas über die Geschichte dieses Wortes "im deutschen Sprachgeiste" zu erfahren, so entdeckt man, daß es ursprünglich "ohne tadelnden Sinn" mit freier Wahl oder Entschließung gleichbedeutend war. Erst von der zweiten Hälfte des achtzehnten Jahrhunderts an wird Willkür im Gegensatz zum bewußten, vernünftigen Willen definiert. Man ist versucht, an diesem Bedeutungswechsel ein Stück Geschichte abzulesen. Grimms Belege legen die Vermutung nahe, daß das Wort in dem geschichtlichen Augenblick negativ besetzt wird, wo das Bürgertum im Namen einer allgemeinen, gesetzgebenden Vernunft feudale Privilegien verurteilt. Stimmt diese Vermutung, dann ergibt sich folgende Paradoxie. Der pejorative Gebrauch des Wortes entspringt dem bürgerlichen Befreiungskampf gegen feudales Unrecht, um dann bei Benjamin gegen das Bürgertum gekehrt zu werden. Spricht Benjamin in der "Aufgabe des Übersetzers" vom "heilige [n] Wachstum" der Sprachen "bis ans messianische Ende ihrer Geschichte" (GS, IV.1, S. 14), so scheint das "Aufleben" dieses Wortes bei Benjamin unterirdisch mit der Dialektik des Klassenkampfes zu kommunizieren.

16. GS, I.2, S. 694.

17. GS, I.1, S. 49.

18. Diese Entkräftung der Sprache - so ließe sich Benjamins Überlegung weiterspinnen - wird durch eine Linguistik rationalisiert, welche die synchrone Struktur der Sprache unter Ausklammerung ihrer diachronen Geschichte herausarbeitet. Unter dem formalistischen Blick erstarren die "Formen des in ihr verschlossenen Lebens". Der Strukturalismus überblickt räumliche Formen, aber übersieht dabei die zeitlichen Kräfte, die sie beleben.

19. GS, I.2, S. 647. Benjamin definiert Aura auch als "einmalige Erscheinung einer Feme, so nah sie sein mag" (GS, I.2, S. 480). Die Erfahrung der Aura beruht auf der "Übertragung einer in der menschlichen Gesellschaft geläufigen Reaktionsform auf das Verhältnis des Unbelebten oder der Natur zum Menschen". Aber "Worte können auch ihre Aura haben. Karl Kraus hat sie so beschrieben: 'Je näher man ein Wort ansieht, desto ferner sieht es zurück'” (a.a.O., S. 646-647).

20. Die Sprache wird in der "Lehre vom Ähnlichen" als ein "Medium" beschrieben, "in dem sich die Dinge nicht mehr direkt wie früher in dem Geist des Sehers oder Priesters sondern in ihren Essenzen, flüchtigsten und feinsten Substanzen, ja Aromen begegnen und zu einander in Beziehung treten" (GS, II.1, S. 209).

21. GS, I.2, S. 694-695.

22. GS, I.2, S. 704.

23. GS, I.1, S. 89.

24. GS, II.1, S. 204.

25. GS, I.2, S. 693.

26. GS, I.1, S. 216.

27. Die Zeilen, die Benjamin 1924 an Hofmannsthal richtet, könnten Hannah Arendt zufolge "aus einer Schrift von Heidegger aus den vierziger oder fünfziger Jahren" stammen (Benjamin, Brecht (München, 1971), S. 58). Vgl. zu einer ähnlichen Problematik Hermann Mörchen, Adorno und Heidegger: Untersuchung zu einer philosophischen Kommunikationsverweigerung (Stuttgart, 1981). Gegenseitige Allergien sprechen am allerletzten gegen solche eventuellen Familienähnlichkeiten. Was eher zu denken gibt, ist Adornos Bemerkung, daß unsere Großeltern auf alten Photos alle gleich aussehen. 
28. Vgl. die Eingangsstrophen von zwei Baudelaire-Gedichten:

La Nature est un temple où de vivants piliers

Laissent parfois sortir de confuses paroles;

L'homme y passe à travers des forêts de symboles

Qui l'observent avec des regards familiers.

(Correspondances)

J'ai longtemps habile sous de vastes portiques

Que les soleils marins teignaient de mille feux,

Et que leurs grands piliers droits et majestueux,

Rendaient pareils. le soir, aux grottes basaltiques.

(La Vie anterieure)

Einen weiteren Vergleich bietet die Stelle aus Shakespeares "Sturm" an, die Arendt in ihrem Benjamin-Aufsatz zitiert:

Full fathom five thy father lies,

of his bones are coral made,

These are pearls that were his eyes.

Nothing of him that doth fade

But doth suffer a sea-change

Into something rich and strange.

Benjamins Charakterisierung der Aura als "ein 'vergessenes Menschliches'” (B, 2, 849) wäre hier anzuschließen, sowie der Satz von Novalis: "In allen Prädikaten, in denen wir das Fossil sehen, sieht es uns" (zit., GS, I.1, S. 55).

29. GS, I.1, S. 227 und 207. Vgl. zum "Wissenschaftsbetrieb": B, 2, S. 523.

30. Vgl. zur analogen Rollenvertauschung, die im Dornröschen enthalten ist, das Benjamin seiner gescheiterten Habilitationsschrift nachschickt, Verf., "Hors d'Oeuvre", in: Walter Benjamin, Origine du drame baroque allemand (Paris, 1985), S. 7-21.

31. GS, II.1, S. 143-144.

32. A.a.O., S. 150. Vgl. zur Problematik des Sprachsündenfalls Verf., "Sur quelques motifs juifs chez Benjamin”, in: Revue d'Esthétique (Paris, Oktober 1981), S. 141-161.

33. Zit., GS, I.2, S. 701.

34. GS, II.1, S. 150. Namen und Ideen sind "nicht sowohl in einer Ursprache, denn in einem Urvernehmen" gegeben, "in welchem die Worte ihren benennenden Adel unverloren an die erkennende Bedeutung besitzen. [...] Im empirischen Vernehmen, in welchem die Worte sich zersetzt haben, eignet nun neben ihrer mehr oder weniger verborgenen symbolischen Seite ihnen eine offenkundige profane Bedeutung. Sache des Philosophen ist es, den symbolischen Charakter des Wortes, in welchem die Idee zur Selbstverständigung kommt, die das Gegenteil aller nach aussen gerichteten Mitteilung ist, durch Darstellung in seinen Primat wieder einzusetzen" (GS, I.1, S. 216-217).

35. GS, II.1, S. 157.

36. A.a.O., S. 149.

37. GS, I.1, S. 217.

38. Vgl. dagegen die Kritik am sprachwissenschaftlichen Formalismus bei M. Bakhtin und/oder V.N. Voloshinov, in: Marxismus und Sprachphilosophie: Grundlegende Probleme der soziologischen Methode in der Sprachwissenschaft (Berlin, 1971). Während Benjamin die bürgerliche Sprachwissenschaft unter anderem als eine Theorie zwischenmenschlicher Mitteilung verurteilt, wird sie von Bakhtin/ Voloshinov angegriffen, weil sie keine solche Theorie erstellt. Sie leide nämlich am selben "Monologismus" wie die adamitische Sprachtheorie. In Wahrheit geraten die Worte unterwegs zu den Dingen - so Bakhtin/ Voloshinov - in ein dialogisches Kraftfeld. Eine adamitische Situation zu unterstellen, in der eine einzige Stimme die Dinge bezeichne, sei deshalb eine willkürliche Fiktion. Während Bakhtin/ Voloshinov den - stalinistischen - 
Monologismus im Namen eines emanzipatorischen Dialogismus angreifen, greift Benjamin im Kampf gegen das "Geschwätz" einer "ewig diskutierenden Klasse" auf die monologische Autorität des höheren Machtworts oft zurück. "Ohne die Anwesenden anzuschauen", schreibt Gershom Scholem von seinem Auftreten im "Sprechsaal der Jugend", "sprach er mit großer Intensität und durchaus druckfertig in eine obere Ecke des Saales hinein, die er die ganze Zeit über unverwandt fixierte" (Walter Benjamin - die Geschichte einer Freundschaft (Frankfurt, 1975), S. 10). Auch das Kunstwerk nimmt Benjamin zufolge keine "Rücksicht auf den Aufnehmenden": "Denn kein Gedicht gilt dem Leser, kein Bild dem Beschauer, keine Symphonie der Hörerschaft" (GS, IV.1, S. 9).

39. GS, II.1, S. 154.

40. A.a.O.

41. A.a.O., S. 153.

42. GS, I.1, S. 407.

43. GS, II.1, S. 153.

44. A.a.O.

45. GS, II.1, S. 154.

46. GS, II.1, S. 155.

47. Vgl. etwa zur Problematik des Zeichens: Max Horkheimer und Theodor W. Adorno, Dialektik der Aufklärung (Frankfurt, 1978), S. 19 ff. Das Zeichen wird hier nicht mehr dem Namen, sondern dem Bilde gegenübergestellt. Dabei werden zwei sprachphilosophische Motive Benjamins - das Zeichen und das mimetische Vermögen - zusammengedacht.

48. GS, I.1, S. 342 .

49. In seinem Aufsatz "Über Wahrheit und Lüge im außermoralischen Sinn" legt Nietzsche den Gedanken nahe, daß die bürgerliche Auffassung der Sprache als ein System verabredeter Zeichen mit der bürgerlichen Theorie des gesellschaftlichen Vertrags konvergiert. Letzterer soll seine Kontrahenten vor der gesetzlosen Willkür schützen, die vorangegangen sei. Das System verabredeter Zeichen wäre in diesem Sinn der Versuch, Ordnung ins Chaos der Sprachverwirrung hineinzubringen. Verkehrschaos und Verkehrsordnung, Willkür und Verabredung wären Wechselbegriffe.

50. Einerseits hebt Benjamin die magische Komponente der profanen, scheinbar entzauberten Zeichensprache hervor. (Etwa in Analogie zur Freudschen Wiederkehr des Verdrängten - einem Modell, das auch der Dialektik der Aufklärung zugrunde liegt). Andererseits stellt er im Aufsatz “ Über das mimetische Vermögen" das Modell einer gelungenen Entmythologisierung auf. Als das "vollkommenste Archiv der unsinnlichen Ähnlichkeit" ist die Sprache "ein Medium, in welches ohne Rest die früheren Kräfte mimetischer Hervorbringung und Auffassung hineingewandert sind, bis sie so weit gelangten, die der Magie zu liquidieren" (GS, II.1, S. 213). Die zwei großen Paradigmen, die einander hier gegenüberstehen, lassen sich schwerlich unter einen Hut bringen. Im einen Falle hätte keine Entmythologisierung stattfinden sollen, denn sie konnte nur eine Verfallsgeschichte sein. Im anderen Fall wird eine positive Alternative vorgestellt. Eine exemplarische Entmythologisierung soll schon innerhalb der Sprache stattgefunden haben. Es handelt sich dabei eben nicht um einen "Verfall", sondern um eine "Transformierung" (a.a.O., S. 211) des mimetischen Vermögens: gelungene Sublimierung, anstatt mißlungener Verdrängung. Wie weit Benjamins mimetische Sprachauffassung vom Konventionalismus abführen kann, geht besonders deutlich aus seinen Gesprächen mit Jean Selz hervor: "Eines Tages”, berichtet dieser, “ überraschte er mich mit der verblüffenden Behauptung, alle Wörter, gleich welcher Sprache, glichen in ihrem Schriftbild dem Ding, das sie bezeichneten. [...] Dann sprach er das deutsche Wort 'rot' vor sich hin und fand: 'Das Wort 'rot' ist so etwas wie ein Schmetterling, der sich auf jede Nuance der roten Farbe niedersetzt'. Ein wenig später zog das rote Taschentuch seine Aufmerksamkeit an, und er machte die Bemerkung: 'Für mich steht es zwischen 'torche' (Fackel) und 'torchon' (Handtuch)'. So stellte er zwischen zwei Wörtern wieder eine Beziehung her, die 
sich von ihrem gemeinsamen Ursprung aus (torquere, tordre) im Sinn voneinander entfernt hatten. [...] Einem Won einen Auftrieb zu geben, am Zusammenstoß zweier Wörter ihre innerste Übereinstimmung blitzartig zu zeigen und die Dinge zu zwingen, ihr Geheimnis preiszugeben, waren in seinen Augen wesentliche Aufgaben des Schriftstellers" (Über Walter Benjamin (Frankfurt, 1968), S. 40-41). Diese letzte Formulierung verweist wieder auf die grundsätzliche Parallele zwischen Benjamins Sprach- und Geschichtsphilosophie. Die "geheime Verabredung", die zwischen "Geschlechtern" besteht, erstreckt sich auch auf Wörter. Sie findet im flüchtigen Augenblick einer unwillkürlichen Erinnerung statt. Ist der "Sinnzusammenhang" eines Textes der "Fundus", aus dem ein "Bild" "blitzhaft" zum Vorschein kommt (GS, II.1, S. 209), so "blitzt" “ das wahre Bild der Vergangenheit" aus dem linearen Verlauf der Geschichte "auf” (GS, I.2., S. 695). - Die von Selz überlieferten Spekulationen sind Beispiele jenes "Kratylismus", dessen lange Geschichte Gerard Genette in einem eindrucksvollen Buch (Mimologiques, Paris 1975) ausführlich dokumentiert hat. Sein Untertitel lautet: Voyage en Cratylie. Für Genette, der am arbitraire du signe nicht zweifelt, ist der "Kratylismus" im Grunde ein poetischer Kinderglaube, der streng wissenschaftlichen Kriterien nicht standhält. Auf die Grundsatzdebatte, die sich aus einer Gegenüberstellung zwischen Genettes und Benjamins Positionen ergibt, werden wir an anderer Stelle eingehen.

51. GS, II.1, S. 153.

52. GS, I.2, S. 683.

53. Das wäre die "Genese" einer Linguistik, die von genetischen Fragen nichts wissen will. Sie klammert jegliche Diachronie aus, die sie mit "Historismus" gleichsetzt, um die synchrone Struktur der Sprache herausarbeiten zu können. Demgegenüber entwickelt die Erkennmiskritische Vorrede zum Trauerspielbuch eine Ideenlehre, die solche Alternativen nicht anerkennt. In der "kristallinischen Simultaneität" (GS, I.1, S. 218) der Idee soll die "Totalität ihrer Geschichte vollendet" daliegen (a.a.O., S. 226). Benjamins eigene Kritik des Historismus taucht in diesem Zusammenhang schon auf (a.a.O., S. 234).

54. 11 ferait volontiers de la terre un debris

Et dans un bäillement avalerait le monde;

(Baudelaire, Au Lecteur)

55. GS, II.1, S. 153.

56. Eine der vielen profanen Gegenfragen, die die hier inkriminierte Sprachwissenschaft aufwerfen könnte: Wie wäre wohl die paradiesische Namenssprache, deren innigster Anteil am göttlichen Logos der "Eigenname" (GS, II.1, S. 149) sei, linguistisch zu erfassen? Da sie dem “ Urteil" vorausgeht, das als "Wissen um Gut und Böse" (GS, I.1, S. 407) erst im Sündenfall entsteht, scheint sich diese vollkommenste aller Sprachen auf eine gewisse Anzahl ("Deren benannte Vielheit ist zählbar", GS, II.1, S. 218) von Hauptwörtern zu beschränken, die wohl alle letztlich im Namen des einen wahren Gottes gründen. Wie die Engel, die "vor Gott ihren Hymnus" (GS, II.1, S. 246) singen, spricht Adam mit jedem Worte ein Halleluja aus, das am "ununterbrochene[n] Strom " (GS, II.1, S. 157) des göttlichen Logos teilnimmt. Diese Ursprache kennt keinen Aufschub. Keine Syntax kommt dazwischen, um ihre Kontinuität zu unterbrechen. Zwischen Name und Ding, die zwei Modi des göttlichen Logos sind, soll ein unmittelbares Verhältnis herrschen. Benjamins monologische Sprachtheologie ist m.a.W. der reine Fall einer metaphysique de Ia présence. Vgl. dazu u.a. Jacques Derridas Abhandlung "La Mythologie Blanche" (in: Marges de Ia Philosophie (Paris, 1972)), insbesondere den Abschnitt “Les Fleurs de la Rhetorique: L'Heliotrope" (S. 295 ff.), wo eine schon bei Aristoteles vorkommende Bevorzugung des Hauptworts auf ihre metaphysischen Prämissen hin untersucht wird. - Die grammatikalische Dimension der Sprache fällt ebenfalls im Aufsatz "Über das mimetische Vermögen" aus. Vom Strukturalismus her gesehen wird die Diachronie auf Kosten des Systems privilegiert. Im Sinne Roman Jakobsons käme nur der metaphorische, nicht der metonyme Pol der Sprache vor, was - bei einem Gegner der Amnesie! - einem Typus von Aphasie entspräche, die Jakobsen le trouble de Ia continuite nennt (“ 
Deux aspects du Iangage et deux types d'aphasie", in: Essais de Linguistique Generale (Paris, 1963), S. 43-67, insbes. S. 56-67). Vgl. dazu Derrida, a.a.O., S. 255.

57. Zit., GS, II.1, S. 240.

58. B, 2, S. 659.

59. GS, II.2, S. 689. Mit dieser Metapher beschreibt Benjamin ein Jahr zuvor nicht sich, sondern Sowjetrußland. Aber sein Programm besteht eben darin, sein Denken der Revolution anzugleichen.

60. Vgl. dazu Scholem, a.a.O., S. 35-72.

61. GS, I.2, S. 697-698.

62. A.a.O., S. 695.

63. "Das Staunen darüber, daß die Dinge, die wir erleben, im zwanzigsten Jahrhundert 'noch' möglich sind, ist kein philosophisches" (a.a.O., S. 697).

64. Analog hat Kafka "in dem Spiegel, den die Vorwelt ihm in Gestalt der Schuld entgegenhielt, die Zukunft in Gestalt des Gerichts erscheinen sehen" (GS, II.2, S. 427)

65. GS, I.3, S. 1235.

66. GS, I.1, S. 405.

67. Angesichts dieses Unheils greift auch Brecht, der plumpe Materialist, auf religiöse Bilder zurück: "Bedenkt das Dunkel und die große Kälte $I$ In diesem Tale, das vor Jammer schallt” (zit., GS, I.2, S. 696).

68. GS, I.1, S. 343.

69. Diese Mißgestalt wäre vielleicht mit dem Motiv des Buckels in Beziehung zu setzen. Ist die Weltgeschichte eine Fehlgeburt, so ähnelt der Bucklige einem Fötus. Als das "Urbild” einer “ Entstellung”, die dem Vergessen entspringt (GS, II.2, S. 431), verkörpert auch der Buckel “ Unzeitiges, Leidvolles, Verfehltes von Beginn an”. Der Rückstand des Vergessens, den er auf dem Rücken trägt, ist die Schuld der Weltgeschichte. Vgl. dazu Verf., “'Märchen für Dialektiker'. Walter Benjamin und sein bucklicht Männlein”, in: Walter Benjamin und die Kinderliteratur, hrsg. von Klaus Doderer (Weinheim, 1988).

70. GS, II.2, S. 436.

71. GS, II.1, S. 153.

72. GS, I.2, S. 479.

73. Zit., GS, II.2, S. 432.

74. "Aber das Vergessen betrifft immer das Beste", schreibt Benjamin im Zusammenhang mit Kafka, “denn es betrifft die Möglichkeit der Erlösung” (GS, II.2, S. 434).

75. GS, I.1, S. 313-314.

76. Zit., GS, II.2, S. 428.

77. Ist das erste Anzeichen dieses Sturms das Geräusch der fallenden Blätter, die am "Baum der 'Erkenntnis'” (GS, I.1, S. 407) hängen? "Wie das Rascheln in gefallenen Blättern” klingt jedenfalls bei Kafka das Lachen Odradeks, das Benjamin als die Stimme des Vergessenen deutet. Es wäre das Gegenstück zur Klage der - ebenfalls vergessenen - Natur. "Die Klage ist aber der undifferenzierteste, ohnmächtige Ausdruck der Sprache, sie enthält fast nur den sinnlichen Hauch; und wo auch nur Pflanzen rauschen, klingt immer eine Klage mit" (GS, II.1, S. 153).

78. GS, II.1, S. 154.

79. Der letzte Satz von "Paris, die Hauptstadt des XIX. Jahrhunderts” wäre hier einzublenden: “ Mit der Erschütterung der Warenwirtschaft beginnen wir, die Monumente der Bourgeoisie als Ruinen zu erkennen, noch ehe sie zerfallen sind." Der Turm zu Babel könnte fast als das Urbild solcher Monumente angesehen werden.

80. GS, I.1, S. 313-314.

81. A.a.O., S. 35. 
82. Vgl. dazu den "Ausfall aller Eschatologie" (a.a.O., S. 259) im deutschen Trauerspiel und den Ausfall der Sterne bei Baudelaire (GS, V.1, S. 417, 421).

83. GS, II.1, S. 147.

84. GS, I.1, S. 216.

85. GS, I.1, S. 353. Diese Metaphorik klingt schon einige Seiten vorher an: "Soviel Bedeutung, soviel Todverfallenheit, weil am tiefsten der Tod die zackige Demarkationslinie zwischen Physis und Bedeutung eingräbt" (a.a.O., S. 343). Es paßt zur todverfallenen Schrift der (natur)geschichtlichen Welt, daß die "festlich begangene" Sprache der messianischen Welt die "Fesseln der Schrift gesprengt hat". Mit dieser wiederhergestellten Einheit von Leben, Geist und Sprache, die dem Sündenfall vorausging, ist die "Verwirrung" geschlichtet, die "vom Turm zu Babel herrührt". Die Universalgeschichte, die es erst in der messianischen Welt geben kann, ist also keine geschriebene. Sie ist nichts anderes als die wiedergefundene Universalsprache, "in die jeder Text einer lebenden oder toten zu übersetzen ist" (GS, I.3, S. 1238-1239). Daraus erklärt sich zugleich die messianische Funktion, die der Entzifferung der Schrift zukommt. "Umkehr ist die Richtung des Studiums", heißt es im Kafka-Aufsatz, "die das Dasein in Schrift verwandelt" (GS, II.2, S. 437). Es reicht allerdings nicht aus, die Schrift als "Abcbuch" wie ein "Schüler" abzulesen. Damit begnügt sich der Historismus, der die Begebenheiten nachbuchstabiert. Das graphologische "Vexierbild" soll vielmehr aus dem "buchstäblichen Text" herausgelesen werden (GS, II.1, S. 208-209). Eine solche Lektüre übt der rückgewandte Engel, der die Geschichte "gegen den Strich" (GS, I.2, S. 697) liest. - Zwischen solcher "Graphologie" und der "Grammatologie" besteht ein prinzipieller Gegensatz. Mit seiner Gegenüberstellung von Logos/Leben und Schrift/ Tod knüpft Benjamin an die "logozentrische" Metaphysik an, die Derrida in De la Grammatologie (Paris, 1967) auf ihre Unterdrückung der Schrift hin untersucht hat. Daß der behauptete Gegensatz zwischen Wort und Schrift mit der Unterscheidung zwischen "guter" und "schlechter" Schrift zusammenfällt, scheint sich auch bei Benjamin zu bestätigen. So wird z. B. die "prägende" Gewalt des Namens gegen die sich "aus-" oder "aufprägende" Willkür des Zeichens ausge- spielt. Für diese Fragestellung bietet Benjamins Aufsatz "Zur Kritik der Gewalt" ein besonders aufschlußreiches Material. - Wir wollen an anderer Stelle den fälligen Versuch unternehmen, Benjamin mit Derrida zu konfrontieren. Es sei hier nur angemerkt, 1.) daß Benjamin erklärtermaßen mit onto-theologischen Gegensatzpaaren operiert und vor einer metaphysique de la présence keineswegs zurückscheut; 2.) daß er sich hinsichtlich des historischen Materialismus selber zunehmend gefragt hat, inwieweit die "Theologie", deren Schrift er auslöschen wollte (GS, I.3, S. 1235), noch tragfähig war; 3.) daß sie es bei ihm in einem völlig unwahrscheinlichen Maße tatsächlich noch war - ein enigmatischer Befund, von dem keine Konfrontation zwischen Benjamin und Derrida absehen sollte.

86. Von einer Perspektive aus gesehen, die die Geschichte als Sprachzerfall erscheinen läßt, erweist die überspannte Sprachmoral eines Karl Kraus - wie Fouriers Naturphilosophie - ihren “ überraschend gesunden Sinn". (Vgl. GS, I.2, S. 699)

87. GS, I.2, S. 704.

88. Vgl. zur Zusammenarbeit von Theologie und Materialismus GS, I.2, S. 693.

89. Zit., a.a.O., S. 695. Alles ist Ranke zufolge "unmittelbar zu Gott". Aber der messianische Augenblick einer solchen Übersicht ist nach Benjamin noch nicht gekommen. Die Position des Chronisten, "welcher die Ereignisse hererzählt, ohne große und kleine zu unterscheiden”, fällt “ erst der erlösten Menschheit" zu (a.a.O., S. 694).

90. Vgl. zum theologischen totum simul der strukturalistischen panorographie Derridas Aufsatz “ Force et Signification”, in: L'Ecriture et Ia Différence (Paris, 1967), S. 9-49. Derrida führt aus, wie die Zeit dabei verräumlicht und die Kraft verflacht wird. Benjamin hätte diese Kritik aufgrund ganz anderer Prämissen unterschreiben können. Es ist die "Zeit der Hölle”, die "im Raum säkularisiert " wird (GS, I.1, S. 406). Solche "Säkularisierung der Zeit im Raum" entspricht sowohl der “ allegorischen Anschauung", als auch dem "naturwissenschaftlichen Weltbild" (GS, V.1, S. 590). 
91. GS, I.1, S. 343.

92. Folgender Satz von Maxime du Camp steht als Motto zum zweiten Éxpose der Passagenarbeit: "L'histoire est comme Janus, elle a deux visages: qu'elle regarde le passé ou le présent, elle voit les mêmes choses" (zit., GS, V.1, S. 60). Ein solcher Janusblick mag dem “ Seherblick" des "rückwärts gewandten Propheten" fast bis zum Verwechseln ähnlich erscheinen. Er soll jedoch die Grundillusion des Historismus versinnbildlichen, aus der es gerade zu erwachen gilt. Daß die Phantasmagorie des Immergleichen der Wahrheit zum Greifen nahe kommt, die der Engel der Geschichte vor Augen hat, ist aus dem Verhältnis gleichzeitiger Nähe und Ferne zu erklären, die Traum und Erwachen zueinander unterhalten.

93. GS, I.2, S. 702.

94. A.a.O., S. 695.

95. Vgl. dazu Benjamins Selbstbeschreibung im Jahre 1931: "Ein Schiffbrüchiger, der auf einem Wrack treibt, indem er auf die Spitze des Mastbaums klettert, der schon zermürbt ist. Aber er hat die Chance, von dort zu seiner Rettung ein Signal zu geben" (B, 2, S. 532).

96. GS, I.2, S. 703.

97. A.a.O., S. 696.

98. "Die Vielheit der Historien ist der Vielheit der Sprachen ähnlich. Universalgeschichte im heutigen Sinn kann immer nur eine Art von Esperanto sein. Die Idee der Universalgeschichte ist eine messianische" (GS, I.3, S. 1238).

99. GS, I.1, S. 406.

100. A.a.O.

101. A.a.o

102. GS, I.2, S. 696.

103. "Wie ein Kranker, der im Fieber liegt, alle Worte, die ihm vernehmbar werden, in die jagenden Vorstellungen des Deliriums verarbeitet, so greift der Zeitgeist die Zeugnisse von früheren oder von entlegenen Geisteswelten auf, um sie an sich zu reißen und lieblos in sein selbstbefangenes Phantasieren einzuschließen" (GS, I.1, S. 234). So lautet Benjamins früheste Diagnose des Historismus, der anstelle der "eingestandenen Subjektivität" der Baudelaireschen "tout pour moi devient allégorie" eine "trügerische Objektivität" (GS, I.1, S. 407) aufrecht erhält. Sprachtheologisch betrachtet ist solche egozentrische Gedankenflucht ein weiteres Symptom des Sündenfalls.

104. GS, I.1, S. 343.

105. A.a.O., S. 406. Eine "letzte Phantasmagorie des Objektiven" stellt auch Blanquis Schrift L'Eternité par les Astres dar, die eine naturwissenschaftliche Lehre von der ewigen Wiederkehr enthält. "Ce Iivre parachève la constellation des fantasmagories du siècle par une dernière

fantasmagorie à caractère cosmique, qui implicitement comprend la critique la plus acerbe de toutes les autres" (GS, V.1, S. 75). "In der Idee der ewigen Wiederkunft überschlägt der Historismus des 19ten Jahrhunderts sich selbst" (a.a.O., S,.174). "Wie Stürzende im Fallen sich überschlagen", hieß es im Trauerspielbuch, "so fiele von Sinnbild zu Sinnbild die allegorische Intention dem Schwindel ihrer grundlosen Tiefe anheim, müßte nicht gerade im äußersten unter ihnen so sie umspringen, daß all ihre Finsternis, Hoffart, und Gottferne nichts als Selbsttäuschung erscheint" (GS, I.1, S. 405). Der Historismus, der in Blanquis allegorischer Naturwissenschaft sein äußerstes Sinnbild findet, steht auf der Schwebe des Erwachens. Aber die Finsternis wird sich diesmal nicht als bloße Selbsttäuschung erweisen.

106. A.a.O., S. 407.

107. GS, I.2, S. 702.

108. GS, I.1, S. 360 .

109. GS, V.1, S. 466. "Vorhersagen", fährt Benjamin fort, "läßt das Ergebnis sich nie; denn es gibt keine natürliche Vermittelung zwischen den beiden. Ebenso aber steht es 
mit Ware und Preis. [...] In der Tat heißt die Bedeutung der Ware Preis; eine andere hat sie, als Ware, nicht. Darum ist der Allegoriker mit der Ware in seinem Element". Zahlreiche Notizen des Passagen-Werks stellen eine Beziehung zwischen Allegorie und Warenproduktion her. Die Vermutung, daß die nachparadiesischen Menschen, die sich durch Zeichen verständigen, in der Wüste der bürgerlichen Gesellschaft irren, findet darin eine retrospektive Bestätigung.

110. "Eine Bedeutung, einen Sinn auszustrahlen”, ist das Ding seit dem Sündenfall "ganz unfähig; an Bedeutung kommt ihm das zu, was der Allegoriker ihm verleiht; er legt's in ihn hinein und langt hinunter [...]" (GS, I.1, S. 359). Er "meidet darin keineswegs die Willkür als drastische Bekundung von der Macht des Wissens" (a.a.O., S. 360).

111. Das ist der Gestus des Lumpensammlers. Der Historist ist der schlechte, der historische Materialist der gute Lumpensammler. Vgl. dazu Verf., "Et cetera? Der Historiker als Lumpensammler", in: Passagen. Walter Benjamins Urgeschichte des XIX. Jahrhunderts, hrsg. von Norbert Bolz und Bernd Witte (München, 1984), S. 70-95, insb. S. 84.

112. GS, V.1, S. 594 .

113. Zit. GS, I.2, S. 700.

114. GS, I.3, S. 1238 .

115. GS, I.1, S. 342. Als “das Zeichen, das gegen seine Bedeutung scharf abgesetzt ist” (GS, V.1, S. 473), ist die Allegorie die mise en abyme des Abgrunds, der dem Zeichen innewohnt. Aber nicht im Sinne des Strukturalismus, der im Zeichen nicht das Gewordensein, sondern nur das Sosein der Sprache erblickt und mit dem Abgrund qua struktureller Differenz umzugehen weiß. Sondern im Sinne eines geschärften Organs für das Außersichsein der Sprache. Während der Allegoriker die Willkür seiner Zeichen verzweifelt unterstreicht, geht das Bewußtsein ihrer Leere im sonstigen Verkehr der Zeichen unter. Die Bahn des Fortschritts wäre dieser zubetonierte Abgrund. Daraus ergibt sich folgende Antinomie des bürgerlichen Bewußtseins. Während ihre Ästhetik die Allegorie zugunsten des Symbols entwertet (GS, I.1, S. 336 ff.), weil die schöne Seele von der unschönen Willkür nichts wissen will, besteht ihre Semiologie ebenso ausschließlich auf der Willkür des Zeichens, weil sie die "symbolische Funktion" (GS, II.1, S. 156) der Sprache nicht wahrhaben will. Demnach muß das Symbol innerhalb der Ästhetik, die Willkür innerhalb der Semiologie bekämpft werden. Denn die Allegorie wird im ersten Fall ausgeschlossen, im zweiten aber eingebürgert, und in beiden Fällen verkannt. Da diese Antinomie im alltäglichen Bewußtsein vermutlich die Struktur der Sartreschen mauvaise foi hat, die je nach Bedarf von einem Pol zum andern oszilliert, tritt sie wohl am ehesten in der Form von schillernden Kompromißbildungen in Erscheinung.

116. GS, II.1, S. 153.

117. GS, I.1, S. 409.

118. Vgl. zu dieser Problematik den Aufsatz "Rhetoric of Temporality" von Paul de Man, in: Interpretation: Theory and Practice, hrsg. von Charles Singleton (Baltimore, 1983), S. 191-209); und Verf. "L'esthétique comme préfiguration du matérialisme historique: La Theorie du Roman et Origine du Drame Baroque Allemand", in: Le tournant esthétique en philosophie, hrsg. von Gérard Raulet (Paris, 1988). Vgl. auch zur Schlegelschen "Willkür des Dichters", die "kein Gesetz über sich leide ", als subjektive oder objektive Ironie (GS, I.1, S. 82 ff.)

119. GS, I.1, S. 406.

120. A.a.O., S. 407.

121. Vgl. dazu a.a.O., S. 220 ff. Auch in der Kontroverse zwischen Realismus und Nominalismus, die Benjamin in der Erkenntniskritischen Vorrede zum Trauerspielbuch wieder aufnimmt, werfen beide Seiten einander Willkür vor. Willkür heißt dem Nominalisten die Hypostasierung von Allgemeinbegriffen, dem Platoniker Benjamin dagegen der Nominalismus selber, der sämtliche Universalien in den "Strudel" seiner "Skepsis", sprich: den Abgrund des Sündenfalls hineinzieht.

122. A.a.O., S. 227. 
123. A.a.O., S. 227-228.

124. GS, I.2, S. 703.

125. GS, I.3, S. 1232 .

126. GS, II.2, S. 437.

127. GS, II.1, S. 153.

128. GS, II.2, S. 432.

129. GS, I.1, S. 406. "Also hat das Wissen von dem Bösen gar keinen Gegenstand. Dies ist nicht in der Welt" (a.a.O., S. 407).

130. A.a.O., S. 407.

131. GS, I.2, S. 701.

132. Der Surrealist, der in diesem monotonen Ticken einen Wecker hört, “der jede Minute sechzig Sekunden lang anschlägt" (GS, II.1, S. 310), hat ein ähnliches Verhältnis zur Zeit wie der Allegoriker zur Sprache.

133. Vgl. GS, I.2, S. 636.

134. GS, I.1, S. 313.

135. GS, II.1, S. 154 .

136. GS, I.2, S. 641.

137. A.a.O., S. 696.

138. A.a.O., S. 702.

139. Vgl. GS, I.2, S. 697.

140. Frankfurt 1982 (erste Auflage 1973). Siehe insbes. Marquardts programmatische Einleitung, die Geschichtsphilosophie mit "Gegenneuzeit" (S. 19) gleichsetzt, und folgende für die hier unternommene Benjamin-Deutung zutreffende Bemerkung macht: "Wenn die Neuzeit - nach einer möglichen Definition - die Neutralisierung der biblischen Eschatologie ist, so ist die Geschichtsphilosophie die Rache der neutralisierten Eschatologie an dieser Neutralisierung" (S. 16).

141. In der Zeit vom 19. Dezember 1986, S. 13-14.

142. GS, II.1, S. 155.

143. A.a.O., S. 154.

144. Vgl. etwa GS, I.2, S. 699 und GS, IV.1, S. 146-148.

145. GS, I.2, S. 653.

146. Wie ist z. B. der frühe Sprachaufsatz, der hier zugrundegelegt wurde, mit dem "Theologisch-politischen Fragment" (GS, II.1, S. 203-204) zusammenzudenken? Steht die Welt dort im Zeichen des Sündenfalls, so strahlt hier die Schöpfung so herrlich wie am ersten Tag. Erinnert dieser Zwiespalt an den polaren Gegensatz zwischen Allegorie und Symbol, so stehen diese Pole wohlgemerkt in einem komplementären Verhältnis zueinander: "Während im Symbol mit der Verklärung des Untergangs das transfigurierte Antlitz der Natur im Licht der Erlösung flüchtig sich offenbart, liegt in der Allegorie die facies hippocratica der Geschichte als erstarrte Urlandschaft vor Augen" (GS, I.1., S. 343, Hervorhebung von mir, I.W.).

147. A.a.O., S. $21 \mathrm{ff}$.

148. Vgl. dazu den differenzierten "Exkurs zu Benjamins Geschichtsphilosophischen Thesen”, in: Jürgen Habermas, Der philosophische Diskurs derModerne (Frankfurt, 1986), S. 21-26.

149. B, 2, S. 793.

150. A.a.O., S. 531.

151. B, 1, S. 157.

152. GS, IV.2, S. 1001.

153. GS, I.1, S. 406.

154. A.a.O., und GS, I.2, S. 701.

155. Vgl. Genette a.a.O. Genette zitiert folgenden Satz Charles Nodiers als das"Motto eines jeden Kratylismus”: "Quand [le poète et le linguiste] ne s'entendent pas entre eux, c'est qu'il y a un des 
deux qui n'a pas compris son art et qui n'en sait pas la portée" (S. 180). Dazu fragt Genette skeptisch: "Mais lequel?". Sein Buch entscheidet sich allerdings eindeutig für die konventionalistische Wissenschaft und dementiert damit sein eigenes Motto: "Chaque débat est un jeune et vieux débat; lors même que nous jugeons l'antérieur, il continue de circuler en nous" (Judith Schlanger, Penser la bouche pleine). Denn er faßt den Kratylismus als eine "literarische Gattung" auf, die sich als solche "unter dem entscheidenden Schock [...] der Geburt der Linguistik " hat einbekennen müssen, dabei "(fast) jeden wissenschaftlichen Anspruch" aufgegeben hat, und somit unwiderlegbar geworden ist (S. 427-428). Genette verhält sich dem Kratylismus gegenüber mit der Nachsicht eines großzügigen Siegers, der den verführerischen Charme seines unvernünftigen Gegners keineswegs verkennt.

156. B, 2, S. 762.

157. Vgl. GS, II.2, S. 676-677. Daß der Adressat der kaiserlichen Botschaft abschließend meint, sie sei ein Traum ("Du aber sitzst an Deinem Fenster und erträumst sie Dir, wenn der Abend kommt"), wird von Benjamin kaum berücksichtigt. Ohne die Geschichte deuten zu wollen, spricht er von Kafka als dem "Angeredeten". Die Frage ist jedoch, ob er sich die Anrede lediglich eingeredet hat. In der Parabel "Vor dem Gesetz" wird eine andere Variation dieser Problematik durchgespielt. Diesmal hat der "Mann vom Lande" eine Bestimmung, die angeblich ihm allein vorbehalten ist. Aber was hat er davon?

158. GS, V.1, S. 591.

159. "Über den abgestumpften Schluß materialistischer Untersuchungen (im Gegensatz zum Abschluß des Barockbuches)" (GS, I.2, S. 690).

160. Vgl. zum Begriff der Nüchternheit bei Benjamin Verf., "The Politics of Prose and the Art of Awakening: Walter Benjamin's Version of a German Romantic Motif", in: Glyph 7 (Baltimore, 1980), S. 131-148.

161. Gerade weil der Konventionalismus kein natürliches Verhältnis zwischen Zeichen und Bezeichnetem gelten läßt, ist er imstande, falsche Naturalisierungen gesellschaftlicher Verhältnisse zu entlarven. Erscheint er aus sprachtheologischer Sicht als ein Fetischismus des Zeichens, so ist er in ideologiekritischer Hinsicht geeignet, Fetischismen abzubauen.

\section{ABSTRACTS}

In his article "Die Willkür der Zeichen" (originally published in: Perspektiven kritischer Theorie. Festschrift für Hermann Schweppenhäuser, ed. Christoph Türcke [Lüneburg, 1988], pp. 124-73) Iriving Wohlfarth retraces the role of the conventionalist theory of language within Benjamin's philosophy of language. In this perspective, the central premise of all modern linguistics, namely what Ferdinand de Saussure's Cours de Linguistique Generale terms the "arbitrary nature of the sign", appears as a symptom of what Benjamin calls "the Fall of the spirit of language", its reduction to a mere means of signification and communication.

\section{INDEX}

Keywords: philosophy of language, philosophy of history, Benjamin Walter, de Saussure Ferdinand 